\title{
Climate change mitigation options and directed technical change: A decentralized equilibrium analysis
}

\author{
André Grimaud $^{a}$, Gilles Lafforgue ${ }^{b *}$ and Bertrand Magnéc \\ a Toulouse School of Economics (IDEI and LERNA) and Toulouse Business School, France \\ ${ }^{b}$ Toulouse School of Economics (INRA-LERNA), France \\ ${ }^{c}$ Paul Scherrer Institute (LEA), Villigen PSI, Switzerland
}

June 6, 2008

\begin{abstract}
The paper considers a growth model with climate change and three R\&D sectors dedicated to energy, backstop and CCS (Carbon Capture and Storage) efficiency. First, we characterize the set of decentralized equilibria: to each vector of public tools, a carbon tax and a subsidy to each R\&D sector, is associated a particular equilibrium. Second, we solve the first-best optimum problem and we implement it by computing the vector of optimal tools. Finally, we illustrate the theoretical model using some calibrated functional specifications. In particular, we investigate the effects of various combinations of public policies (including the optimal ones) by determining the deviation of each corresponding equilibrium from the "laisser-faire" benchmark.
\end{abstract}

JEL classification: H23, O32, Q43, Q54, Q55.

Keywords: Climate change, energy, CCS, directed technical change, knowledge pricing.

\footnotetext{
${ }^{*}$ Corresponding author. LERNA, 21 allée de Brienne, 31000 Toulouse - France. E-mail address: glafforg@toulouse.inra.fr. E-mail addresses of other authors: grimaud@cict.fr and bertrand.magne@psi.ch
} 


\section{Introduction}

Emerging green technologies, such as clean coal, CCS (Carbon Capture and Storage) or renewable energy, are crucial for a cost-effective climate change mitigation policy. The relevant appraisal of a climate policy should thus include the appropriate incentives for R\&D investments in carbon-free energies that will drive the substantial technical improvements necessary to their large scale deployment (see Energy Journal, 2006, Special issue on endogenous technical change and the economics of atmospheric stabilization). The strand of literature on economic growth and climate change contains mostly optimization models (see for instance Bosetti et al., 2006; Edenhofer et al., 2005, 2006; Gerlagh 2006; Gerlagh and Van Der Zwaan 2006; Popp, 2004, 2006a, 2006b). In those models, the analysis usually focuses on the optimal trajectories together with the system of prices and economic policies that implements the optimum. A complementary approach to these questions consists in characterizing the equilibrium in the associated decentralized economy.

The study of the decentralized economy offers one major advantage: it allows for the entire characterization of the continuum of all existing equilibria and not only the optimal

one. Indeed, a particular equilibrium is associated with each feasible vector of policy instruments. The approach followed in this paper gives some insights on how the economy reacts to policy changes: when the economy faces one or several market failures, e.g. pollution or insufficient research effort, this characterization of market equilibria reveals crucial for measuring the impacts of economic tools such as environmental taxes, pollution permits or research subsidies. Because of budgetary, socioeconomic or political constraints, the enforcement of first best optimum is usually difficult to achieve for the policy-maker that would rather implement second-best solutions.

The objective of this paper is to complete the literature mentioned above by setting up a general equilibrium analysis, that includes explicitly both the optimal outcome and the decentralized equilibrium. However, the main difficulty of this approach lies in the way the research activity is modeled, in particular the type of innovation goods which are developed as well as their pricing. In the standard endogenous growth theory (Aghion and Howitt, 1998; Romer, 1990...), when an innovation is produced, it is associated with a particular intermediate good. Research is funded by the monopoly profits of intermediate producers who benefit from an exclusive right, like a patent, for the production and the sale of these goods. However, this methodology has two inconvenients. Firstly, the more 
often, embodying knowledge into intermediate goods becomes inextricable in more general computable endogenous growth models with pollution and/or natural resources such as the ones previously mentioned. In addition, those technical difficulties are emphasized when dealing with several research sectors, i.e. when there are several types of specific knowledge, each of them being dedicated to a particular input (resource, labor, capital, backstop...) as it is proposed in Acemoglu (2002). Secondly, new pieces of knowledge, or new ideas, are not necessary associated with tangible intermediate goods. In particular, in new technology sectors as biotechnology or software industries, they are directly embodied into non-tangible goods that Quah (2001) and Scotchmer (2005) call knowledge goods, or information goods.

To circumvent those obstacles, we assume the absence of tangible intermediate goods in research sectors, as it is done for instance by Gerlagh and Lise (2005), Edenhofer et al. (2006) and Popp (2004, 2006a). Therefore, in an equilibrium framework, it reveals necessary to directly price pieces of knowledge. Grimaud and Rougé $(2008)^{1}$ have adapted such a formalization in growth models with polluting resources and environmental concerns. Based on this literature, we propose a method that consists in three points.

First, we define the optimal price of one unit of specific knowledge (associated with the energy or backstop R\&D sectors) as the sum of the marginal profitabilities of this unit in each sector using this specific knowledge: this is the social value of an innovation.

Second, by referring to several empirical studies (see for instance Jones, 1995; Jones and Williams, 1998; Popp, 2004, 2006a), we assume that, in the decentralized economy, the equilibrium price of knowledge is in fact equal to a given proportion of this optimal value, usually on the order of a quarter to a third. This is justified in the standard literature by the presence of several distortions that prevent the decentralized equilibrium to implement the first-best optimum ${ }^{2}$. The overall effect of those distortions causes the market value of an innovation to be lower than the social one.

Third, we assume that the R\&D sectors can be subsidized in order to reduce the gap between these social and market values ${ }^{3}$.

\footnotetext{
${ }^{1}$ See also Grimaud and Tournemaine (2007).

${ }^{2}$ Jones and Williams (2000) exhibit four of them. i) the duplication effect: the R\&D sector does not account for the redundancy of some research projects; ii) the intertemporal spillover effect: inventors do not account for that ideas they produce are used to produce new ideas; iii) the appropriability effect: inventors appropriate only a part of the social value they create; iv) the creative-destruction effect.

${ }^{3}$ According to the OECD Science, Technology and R\&D Statistics, publicly-funded energy R\&D in 2004 among OECD countries amounted to 9.72 billion US\$, which represented $4 \%$ of overall public R\&D budgets. In the United States, energy investments from the private sector have shrunk during the last decade; governmental funding currently represents $76 \%$ of total US energy R\&D expenditures (Nemet and
} 
We develop an endogenous growth model in which energy services can be produced from a polluting non-renewable resource as well as a clean backstop. Moreover, we assume that carbon emissions can be partially released by using a CCS (Carbon Capture and Storage) technology. As formulated by Hoffert et al. (2002), the decarbonization, i.e. the reduction of the carbon content of each fossil fuel unit, i.e. the amount of carbon emitted per unit of primary energy, is intimately linked to sequestration. Carbon capture, sometimes referred to as emissions control (see Kolstad and Toman, 2001), is the way of achieving this decarbonization. This process consists in separating the carbon dioxide from other flux gases during the process of energy production. It is particularly adapted to large-scale centralized power stations but may also indirectly apply to non electric energy supply. Once captured, the gases are then being disposed into various reservoirs. The sequestration reservoirs include depleted oil and gas fields, depleted coal mines, deep saline aquifers, oceans, trees and soils. Those various deposits differ in their respective capacities, their costs of access or their effectiveness in storing the carbon permanently. In this respect, the introduction of some atmospheric pollution cap reinforces i) the recourse to CCS option in the middle run to prevent ceiling exceeding and ii) the necessity to subsidy research to improve CCS efficiency.

We introduce three R\&D sectors, the first one improving the efficiency of energy production, the second one, the efficiency of the backstop and the last one, the efficiency of the sequestration process. With this respect, we have to consider two types of market failures: the pollution from the part of the carbon emissions that are not released by CCS and the research spillovers in each $R \& D$ sector. That is why, in the decentralized equilibrium, we introduce two kinds of economic policy instruments in accordance: an environmental tax on the carbon emissions and a research subsidy for the energy, backstop and CCS R\&D sectors. There is an equilibrium associated to each vector of instruments, which allows to study the impact of one or several policy changes on the equilibrium trajectories. Clearly, when public instruments are optimally set, the equilibrium of the decentralized economy coincides with the first best optimum.

Next, we calibrate the model to fit the world 2005 data. We find that the implementation a carbon tax alone hardly provides any incentive to proceed with $R \& D$ activities. In order to provide enough R\&D incentives, one needs first to correct for the externality by imposing a carbon tax and second by subsidizing the research sectors. Moreover, short Kammen, 2007). 
term investment in carbon-free technology, namely in CCS activities, can become relevant when imposing a stringent cap on carbon accumulation, or equivalently, an higher level of tax. The same kind of conclusion can be extended for the CCS use. Performances of each combination of policy tools in terms of GWP and social welfare are also analyzed.

The article is organized as follows. Section 2 presents the decentralized economy and studies the behavior of agents in each sector. In section 3, we characterize both the decentralized equilibrium and the first-best optimum solutions owing to two sets of conditions. Next, by comparing these two sets of characterizing conditions, we show how the optimum can be implemented by an appropriate system of prices and public tools. In section 4, we derive a selection of numerical results and we conclude in section 5 .

\section{The decentralized economy}

The model presents two interdependent systems, a bio-climatic and an economic system, based on the DICE-07 model (Nordhaus, 2007b) and on the ENTICE-BR model (Popp, 2006a). The second one is an extension of a former version of the first one that integrates ETC (endogenous technical change).

We consider a worldwide economy containing four production sectors: final output, energy services and two primary energy inputs, namely a fossil fuel and a carbon-free backstop. The fossil fuel (e.g. refining industry in the case of oil) is obtained from a polluting non-renewable resource whose combustion yields $\mathrm{CO}_{2}$ emissions. Accumulation of those emissions in the atmosphere acts to increase the mean atmospheric temperature, which is the key element of anthropological climate change. This causes economic damages that are measured in the model as a share of final output. Industrial emissions can be partly sequestered and stored in carbon reservoirs owing to a specific technology. For the sake of simplicity, we postulate that CCS activities are part of the the energy sector, i.e. the fossil fuel user. Production of final energy services, production of backstop and carbon sequestration require some specific knowledges provided by three specific R\&D sectors. We assume that all sectors, except R\&D sectors, are perfectly competitive. The population grows exogenously and is equal to the labor supply. Finally, in order to correct the two types of distortions involved by the model (pollution and research spillovers in each R\&D sector), we introduce two types of policy tools: an environmental tax on the fossil fuel use and a subsidy for each R\&D sector. Note that, because of CCS, the tax applies on the sole part of the carbon emissions which are released into the atmosphere after sequestration, 
and not on the whole flow of industrial emissions. The model is sketched in Figure 1. The following subsection details it sector by sector.

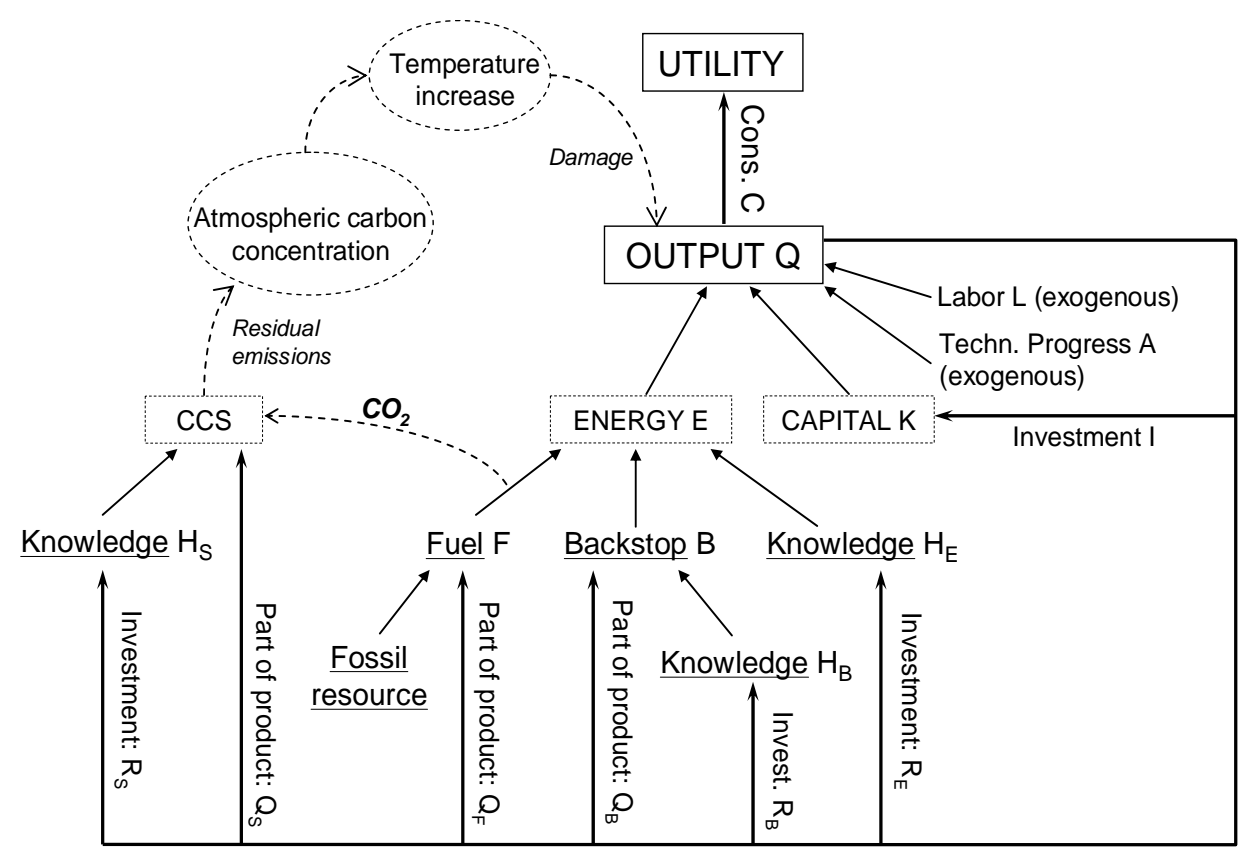

Figure 1: Description of the model

\subsection{Behavior of agents}

\subsubsection{The final good sector}

Production of final output $Q_{t}$ is described by the following modified Cobb-Douglas form:

$$
Q_{t}=Q\left(K_{t}, E_{t}, L_{t}, A_{t}, \Omega_{t}\right)=\Omega_{t} A_{t} K_{t}^{\gamma} E_{t}^{\beta} L_{t}^{1-\gamma-\beta}, \quad \gamma, \beta \in(0,1) .
$$

The gross world product (GWP) first depends on endogenously evolving elements: capital $K_{t}$, energy services $E_{t}$ and a scaling factor $\Omega_{t}$ which accounts from climate-related damages, as discussed below (cf. equation (34)). It also depends on exogenous elements: the total productivity of factors $A_{t} \equiv A_{0} e^{\int_{0}^{t} g_{A, s} d s}$ and the population level $L_{t} \equiv L_{0} e^{\int_{0}^{t} g_{L, s} d s}$. Growth rates $g_{L, t}$ and $g_{A, t}$ are given by $g_{j, t}=g_{j 0} e^{-d_{j} t}$, with $d_{j}>0, \forall j=\{A, L\}$.

Denoting respectively by $p_{E, t}, w_{t}, r_{t}$ and $\delta$ the price of energy services, the real wage, the interest rate ${ }^{4}$ and the depreciation rate of capital, and normalizing to one the price of

\footnotetext{
${ }^{4}$ We assume here that the representative household holds the capital and rents it to firms at a rental price $R_{t}$. Standard arbitrage conditions imply $R_{t}=r_{t}+\delta$.
} 
the final output, we can write the instantaneous profit of producers as: $\Pi_{t}^{Q}=Q_{t}-p_{E, t} E_{t}-$ $w_{t} L_{t}-\left(r_{t}+\delta\right) K_{t}$. Maximizing this profit function with respect to $K_{t}, L_{t}$ and $E_{t}$, subject to (1), we obtain the following first-order conditions:

$$
\begin{aligned}
Q_{K}-\left(r_{t}+\delta\right) & =0 \\
Q_{L}-w_{t} & =0 \\
Q_{E}-p_{E, t} & =0
\end{aligned}
$$

where $J_{X}$ stands for the partial derivative of function $J($.$) with respect to X$.

\subsubsection{The energy-CCS sector}

At each time $t$, the production of energy services $E_{t}$ requires a bundle of imperfect substitute primary energies and some specific knowledge (see Popp, 2006a):

$$
E_{t}=E\left(F_{t}, B_{t}, H_{E, t}\right)=\left[\left(F_{t}^{\rho_{B}}+B_{t}^{\rho_{B}}\right)^{\frac{\rho_{H}}{\rho_{B}}}+\alpha_{H} H_{E, t}^{\rho_{H}}\right]^{\frac{1}{\rho_{H}}}, \quad \alpha_{H}, \rho_{H}, \rho_{B} \in(0,1),
$$

where $F_{t}$ is the fossil fuel use, $B_{t}$ is a backstop energy source and $H_{E, t}$ represents the stock of specific knowledge dedicated to energy efficiency.

The economic and climatic systems are linked in the model by anthropogenic $\mathrm{CO}_{2}$ emissions, generated by fossil fuel burning. Let $\xi$ be the unitary carbon content of fossil fuel such that, without CCS, the carbon flow released into the atmosphere would be equal to $\xi F_{t}$. We assume that, at each date $t$, the CCS device allows a reduction of those emissions by an amount $S_{t}, 0 \leq S_{t} \leq \xi F_{t}$. To change emissions into stored carbon, the sequestration technology needs two inputs, a specific investment $Q_{S, t}$ and some knowledge $H_{S, t}$. This production function takes the following form:

$$
S_{t}=S\left(F_{t}, Q_{S, t}, H_{S, t}\right)=\kappa\left(\xi F_{t}\right)\left[\left(1+\frac{2 Q_{S, t} H_{S, t}}{\kappa\left(\xi F_{t}\right)}\right)^{1 / 2}-1\right], \quad \kappa>0 .
$$

Such a CCS function comes from the sequestration cost function used by Gerlagh and van der Zwaan $(2006)^{5}$. Note that in our model, we consider neither limited capacity of carbon sinks nor leakage problems. Those questions are addressed, for instance, by Lafforgue et al. (2008) and Keller et al. (2007) respectively.

\footnotetext{
${ }^{5}$ In our model, we replace the cost function of fossil fuel and backstop from Popp (2006a) and the cost function of sequestration from Gerlagh (2006) by their corresponding production functions in order to derive an utility/technology canonical model.
} 
Denoting by $p_{F, t}$ and $p_{B, t}$ the prices of fossil fuel and backstop and by $\tau_{t}$ the unit carbon tax on the flow of carbon emissions $\xi F_{t}-S_{t}$, the energy producer must chooses $F_{t}$, $B_{t}$ and $Q_{S, t}$ that maximizes $\Pi_{t}^{E}=p_{E, t} E_{t}-p_{F, t} F_{t}-p_{B, t} B_{t}-Q_{S, t}-\tau_{t}\left(\xi F_{t}-S_{t}\right)$ subject to (5) and (6). The first order conditions write:

$$
\begin{aligned}
p_{E, t} E_{F}-p_{F, t}-\tau_{t}\left(\xi-S_{F}\right) & =0 \\
p_{E, t} E_{B}-p_{B, t} & =0 \\
-1+\tau_{t} S_{Q_{S}} & =0
\end{aligned}
$$

\subsubsection{The fossil fuel sector}

Fossil fuel production depends on a carbon-based non-renewable resource and on specific productive investments (see Grimaud et al., 2007):

$$
F_{t}=F\left(Q_{F, t}, Z_{t}\right)=\frac{Q_{F, t}}{c_{F}+\alpha_{F}\left(Z_{t} / \bar{Z}\right)^{\eta_{F}}}, \quad c_{F}, \alpha_{F}, \eta_{F}>0,
$$

where $Q_{F, t}$ is the amount of GWP devoted to the production of fossil fuel and $Z_{t}$ is the cumulative extraction of the exhaustible resource from the initial date up to $t$ :

$$
Z_{t}=\int_{0}^{t} F_{s} d s \Leftrightarrow \dot{Z}_{t}=F_{t} .
$$

The limited fossil fuel resource base is denoted by $\bar{Z}: Z_{t} \leq \bar{Z}, \forall t \geq 0$. The instantaneous profit of the fuel producer writes $\Pi_{t}^{F}=p_{F, t} F_{t}-Q_{F, t}$ and its program consists in choosing $\left\{Q_{F, t}\right\}_{t=0}^{\infty}$ that maximizes $\int_{0}^{\infty} \Pi_{t}^{F} e^{-\int_{0}^{t} r_{s} d s} d t$, subject to (10) and (11). Denoting by $\eta_{t}$ the multiplier associated with (11), the static and dynamic first-order conditions are:

$$
\begin{aligned}
\left(p_{F, t} F_{Q_{F}}-1\right) e^{-\int_{0}^{t} r_{s} d s}+\eta_{t} F_{Q_{F}} & =0 \\
p_{F, t} F_{Z} e^{-\int_{0}^{t} r_{s} d s}+\eta_{t} F_{Z} & =-\dot{\eta}_{t},
\end{aligned}
$$

together with the transversality condition $\lim _{t \rightarrow \infty} \eta_{t} Z_{t}=0$. Integrating (13) and using (12), it comes:

$$
p_{F, t}=\frac{1}{F_{Q_{F}}}-\int_{t}^{\infty} \frac{F_{Z}}{F_{Q_{F}}} e^{-\int_{t}^{s} r_{x} d x} d s,
$$

which reads as a specific version of the Hotelling rule in the case of an extraction technology given by function (10).

\subsubsection{The backstop sector}

The backstop resource technology is characterized by:

$$
B_{t}=B\left(Q_{B, t}, H_{B, t}\right)=\alpha_{B} Q_{B, t} H_{B, t}^{\eta_{B}}, \quad \alpha_{B}, \eta_{B}>0,
$$


where $Q_{B, t}$ is the amount of GWP that is devoted to the backstop production sector and $H_{B, t}$ is the stock of knowledge pertaining to the backstop. Let $p_{B, t}$ denote the backstop price. At each time $t$, the backstop producer maximizes its profit $\Pi_{t}^{B}=\left[p_{B, t} B_{t}-Q_{B, t}\right]$ subject to (15), which implies the following first-order condition:

$$
p_{B, t} B_{Q_{B}}-1=0 .
$$

\subsubsection{The R\&D sectors}

There are three stocks of knowledge, $H_{E}, H_{B}$ and $H_{S}$, each associated with a specific R\&D sector (i.e. the energy, the backstop and the CCS ones). We consider that each innovation is a non-rival, indivisible and infinitely durable piece of knowledge (for instance, a scientific report, a data base, a software algorithm...) which is simultaneously used by the sector which produces the good $i$ and the R\&D sector $i, i=\{B, E, S\}$.

Here, an innovation is not directly embodied into tangible intermediate goods and thus, it cannot be financed by the sale of these goods. However, in order to fully describe the equilibrium, we need to find a way to assess the price received by the inventor for each piece of knowledge. We proceed as follows: i) In each research sector, we determine the social value of an innovation. Since an innovation is a public good, this social value is the sum of marginal profitabilities of this innovation in each sector using it. If the inventor was able to extract the willingness to pay of each user, he would receive this social value and the first-best optimum would be implemented. ii) In reality, there are some distortions that constrain the inventor to extract only a part of this social value ${ }^{6}$. This implies that the market value (without subsidy) is lower than the social one. iii) The research sectors are eventually subsidized in order to reduce the gap between the social and the market values of innovations.

Let us apply this three-steps procedure to the $\mathrm{R} \& \mathrm{D}$ sector $i, i=\{B, E, S\}$. Each innovation produced by this sector is used by the R\&D sector $i$ itself as well as by the production technology of good $i$. Thus, at each date $t$, the instantaneous social value of this innovation is $\bar{v}_{H_{i}, t}=\bar{v}_{H_{i}, t}^{i}+\bar{v}_{H_{i}, t}^{H_{i}}$, where $\bar{v}_{H_{i}, t}^{i}$ and $\bar{v}_{H_{i}, t}^{H_{i}}$ are the marginal profitabilities of this innovation in the production and $\mathrm{R} \& \mathrm{D}$ sectors $i$, respectively. The social value of this innovation at $t$ is $\bar{V}_{H_{i}, t}=\int_{t}^{\infty} \bar{v}_{H_{i}, s} e^{-\int_{t}^{s} r_{x} d x} d s$. We assume that, without any public intervention, only a share $\gamma_{i}$ of the social value is paid to the innovator, with $0<\gamma_{i}<1$.

\footnotetext{
${ }^{6}$ For instance, Jones and Williams, 1998, estimate that actual investment in research are at least four times below what would be socially optimal; on this point, see also Popp, 2006a.
} 
However, the government can decide to grant this R\&D sector by applying a non-negative subsidy rate $\sigma_{i, t}$. Note that if $\sigma_{i, t}=1-\gamma_{i}$, the market value matches the social one. The instantaneous market value (including subsidy) is:

$$
v_{H_{i}, t}=\left(\gamma_{i}+\sigma_{i, t}\right) \bar{v}_{H_{i}, t},
$$

and the market value at date $t$ is:

$$
V_{H_{i}, t}=\int_{t}^{\infty} v_{H_{i}, s} e^{-\int_{t}^{s} r_{x} d x} d s
$$

Note that differentiating (18) with respect to time leads to the usual arbitrage relation:

$$
r_{t}=\frac{\dot{V}_{H_{i}, t}}{V_{H_{i}, t}}+\frac{v_{H_{i}, t}}{V_{H_{i}, t}}, \quad \forall i=\{B, E, S\}
$$

which reads as the equality between the rate of return on the financial market and the rate of return on the R\&D sector $i$.

We can now analyze the behaviors of the R\&D sectors. The dynamics of the stock of knowledge in sector $i$ is governed by the following innovation function $H^{i}($.$) :$

$$
\dot{H}_{i, t}=H^{i}\left(R_{i, t}, H_{i, t}\right)=a_{i} R_{i, t}^{b_{i}} H_{i, t}^{\phi_{i}}, \quad a_{i}>0, b_{i}, \phi_{i} \in[0,1], \forall i=\{B, E, S\}
$$

where $R_{i, t}$ is the $\mathrm{R} \& \mathrm{D}$ investment into sector $i$, i.e. the amount of final output that is devoted to R\&D sector $i$. At each time $t$, sector $i$ supplies the flow of innovations $\dot{H}_{i, t}$ at price $V_{H_{i}, t}$ and demands some specific investment $R_{i, t}$ at price 1 , so that the profit function to be maximized is $\Pi_{t}^{H_{i}}=V_{H_{i}, t} H^{i}\left(R_{i, t}, H_{i, t}\right)-R_{i, t}$. The first-order condition implies:

$$
V_{H_{i}, t}=\frac{1}{H_{R_{i}}^{i}} .
$$

The marginal profitability of innovations in the R\&D sector $i$ is:

$$
\bar{v}_{H_{i}, t}^{H_{i}}=\frac{\partial \Pi_{t}^{H_{i}}}{\partial H_{i, t}}=V_{H_{i}, t} H_{H_{i}}^{i}=\frac{H_{H_{i}}^{i}}{H_{R_{i}}^{i}} .
$$

Finally, in order to determine the social and the market values of an innovation in each R\&D sector, we need to know the marginal profitability of innovations in the corresponding production sector. From the expressions of $\Pi_{t}^{B}$ and $\Pi_{t}^{E}$, those values are given respectively by $\bar{v}_{H_{B}, t}^{B}=\partial \Pi_{t}^{B} / \partial H_{B, t}=B_{H_{B}} / B_{Q_{B}}, \bar{v}_{H_{E}, t}^{E}=\partial \Pi_{t}^{E} / \partial H_{E, t}=E_{H_{E}} / E_{B} B_{Q_{B}}$ and $\bar{v}_{H_{S}, t}^{E}=$ $\partial \Pi_{t}^{E} / \partial H_{S, t}=\tau_{t} S_{H_{S}}$. Therefore, the instantaneous market values (including subsidies) of 
innovations are:

$$
\begin{aligned}
& v_{H_{B}, t}=\left(\gamma_{B}+\sigma_{B, t}\right)\left(\frac{B_{H_{B}}}{B_{Q_{B}}}+\frac{H_{H_{B}}^{B}}{H_{R_{B}}^{B}}\right) \\
& v_{H_{E}, t}=\left(\gamma_{E}+\sigma_{E, t}\right)\left(\frac{E_{H_{E}}}{E_{B} B_{Q_{B}}}+\frac{H_{H_{E}}^{E}}{H_{R_{E}}^{E}}\right) \\
& v_{H_{S}, t}=\left(\gamma_{S}+\sigma_{S, t}\right)\left(\tau_{t} S_{H_{S}}+\frac{H_{H_{S}}^{S}}{H_{R_{S}}^{S}}\right) .
\end{aligned}
$$

\subsubsection{The household and the government}

The social welfare function is given by:

$$
W=\int_{0}^{\infty} U\left(C_{t}\right) e^{-\rho} d t=v_{1} \int_{0}^{\infty} L_{t} \frac{\left(C_{t} / L_{t}\right)^{1-\epsilon}}{(1-\epsilon)} e^{-\rho} d t+v_{2},
$$

where $\rho>0$, is the pure rate of social time preferences, $U\left(C_{t}\right)$ is the instantaneous utility function, $\epsilon>0$, is the elasticity of marginal utility, i.e. $\epsilon \equiv-C_{t} U^{\prime \prime}\left(C_{t}\right) / U^{\prime}\left(C_{t}\right)$, and $v_{1}, v_{2}>0$ are scaling parameters. The households maximize $W$ subject to the following dynamic budget constraint:

$$
\dot{K}_{t}=r_{t} K_{t}+w_{t} L_{t}+\Pi_{t}-C_{t}-T_{t}^{a},
$$

where $\Pi_{t}$ is the total profits gained in the economy and $T_{t}^{a}$ is a lump-sum tax (subsidy-free) that allows to balance the budget constraint of the government. This maximization leads to the following condition:

$$
\rho-\frac{\dot{U}^{\prime}\left(C_{t}\right)}{U^{\prime}\left(C_{t}\right)}=r_{t} \Rightarrow U^{\prime}\left(C_{t}\right)=U^{\prime}\left(C_{0}\right) e^{\rho t-\int_{0}^{t} r_{s} d s} .
$$

Assuming that the government's budget constraint holds at each time $t$ (i.e. sum of the various taxes equal $R \& D$ subsidies), then it writes:

$$
T_{t}^{a}+\tau_{t}\left(\zeta F_{t}-S_{t}\right)=\sum_{i} \frac{\sigma_{i}}{\left(\gamma_{i}+\sigma_{i}\right)} V_{H_{i}, t} \dot{H}_{i, t}, \quad i=\{B, E, S\}
$$

Finally, remark that expanding $\Pi_{t}=\Pi_{t}^{Q}+\Pi_{t}^{E}+\Pi_{t}^{B}+\Pi_{t}^{F}+\Pi_{t}^{H_{B}}+\Pi_{t}^{H_{E}}$ into (27) and replacing $T_{t}^{a}$ by its value coming from (29), we obtain:

$$
Q_{t}=C_{t}+Q_{F, t}+Q_{B, t}+Q_{S, t}+I_{t}+R_{E, t}+R_{B, t}+R_{S, t}
$$

where $I_{t}$ is the instantaneous investment in capital defined by:

$$
I_{t}=\dot{K}_{t}+\delta K_{t}
$$

Hence, we verify that the final output is devoted to the aggregated consumption, the fossil fuel production, the backstop production, the sequestration device, the investment in capital, and in the three $\mathrm{R} \& \mathrm{D}$ sectors. 


\subsection{The environment and damages}

Let $G_{0}$ be the stock of carbon in the atmosphere at the beginning of the planning period, $G_{t}$ the stock at time $t$ and $\zeta, \zeta>0$, the natural rate of decay. The increase in atmospheric carbon concentration drives the global mean temperature away from a given state - here the 1900 level - and the difference between this state and the present global mean temperature is taken as an index of anthropogenic climate change. Let $T_{t}$ denote this difference. The climatic dynamic system under reduced form can be captured by the following two state equations:

$$
\begin{aligned}
\dot{G}_{t} & =\xi F_{t}-S_{t}-\zeta G_{t} \\
\dot{T}_{t} & =\Phi\left(G_{t}\right)-m T_{t}=\alpha_{G} \log G_{t}-m T_{t}, \quad \alpha_{G}, m>0
\end{aligned}
$$

Function $\Phi($.$) , which links the atmospheric carbon concentration to the dynamics of tem-$ perature, is in fact the reduced form of a more complex radiative forcing function that takes into account the inertia of the climate dynamics ${ }^{7}$.

Global warming yields economic damages that are specified in proportion to the GWP through the scaling factor $\Omega$ (cf. equation (1)):

$$
\Omega_{t}=\Omega\left(T_{t}\right)=\left[1+\alpha_{T} T_{t}^{2}\right]^{-1}, \quad \alpha_{T}>0 .
$$

In addition to the damage reflected by $\Omega_{t}$, we will be induced to impose a stabilization cap on the carbon pollution stock that society can not overshoot (see for instance Chakarvorty et al., 2006):

$$
G_{t} \leq \bar{G}, \quad \forall t \geq 0
$$

This additional constraint can be justified by assuming that the social damage function is not able to reflect the entire environmental damages, but only part of it. In reality, uncertainty in the climatic consequences of global warming can imply some discontinuities in the damage, such as natural disasters or other strong irreversibilities, that are not taken into account by the standard functional representation of the damage.

\footnotetext{
${ }^{7}$ In the analytical treatment of the model, we assume for the sake of clarity that the carbon cycle through atmosphere and oceans as well as the dynamic interactions between atmospheric and oceanic temperatures, are captured by the reduced form (32) and (33). Goulder and Mathai (2000), or Kriegler and Bruckner (2004), have recourse to such simplified dynamics. From DICE-99, the formers estimate parameters $\xi$ and $\zeta$ that take into account the inertia of the climatic system. They state that only $64 \%$ of current emissions actually contribute to the augmentation of atmospheric $\mathrm{CO}_{2}$ and that the portion of current $\mathrm{CO}_{2}$ concentration in excess is removed naturally at a rate of $0.8 \%$ per year. However, in the numerical simulations, we adopt the full characterization of the climate dynamics from the DICE-07 model.
} 


\section{Decentralized equilibrium and welfare analysis}

\subsection{Characterization of the decentralized equilibrium}

From the previous analysis of individual behaviors, we can now characterize an equilibrium in the decentralized economy, which is done by the following Proposition:

Proposition 1 For a given quadruplet of policies $\left\{\sigma_{B, t}, \sigma_{E, t}, \sigma_{S, t}, \tau_{t}\right\}_{t=0}^{\infty}$, the equilibrium conditions can be summed up as follows:

$$
\begin{aligned}
{\left[Q_{E} E_{F}-\frac{\left(\xi-S_{F}\right)}{S_{Q_{S}}}-\frac{1}{F_{Q_{F}}}\right] U^{\prime}(C) e^{-\rho t}+\int_{t}^{\infty} \frac{F_{Z}}{F_{Q_{F}}} U^{\prime}(C) e^{-\rho s} d s } & =0 \\
Q_{E} E_{B} B_{Q_{B}} & =1 \\
\tau_{t} S_{Q_{S}} & =1 \\
Q_{K}-\delta & =\rho-\frac{\dot{U}^{\prime}(C)}{U^{\prime}(C)} \\
-\frac{\dot{H}_{R_{B}}^{B}}{H_{R_{B}}^{B}}+\left(\gamma_{B}+\sigma_{B, t}\right)\left(\frac{B_{H_{B}} H_{R_{B}}^{B}}{B_{Q_{B}}}+H_{H_{B}}^{B}\right) & =\rho-\frac{\dot{U}^{\prime}(C)}{U^{\prime}(C)} \\
-\frac{\dot{H}_{R_{E}}^{E}}{H_{R_{E}}^{E}}+\left(\gamma_{E}+\sigma_{E, t}\right)\left(\frac{E_{H_{E}} H_{R_{E}}^{E}}{E_{B} B_{Q_{B}}}+H_{H_{E}}^{E}\right) & =\rho-\frac{\dot{U}^{\prime}(C)}{U^{\prime}(C)} \\
-\frac{\dot{H}_{R_{S}}^{S}}{H_{R_{S}}^{S}}+\left(\gamma_{S}+\sigma_{S, t}\right)\left(\frac{S_{H_{S}} H_{R_{S}}^{S}}{S_{Q_{S}}}+H_{H_{S}}^{S}\right) & =\rho-\frac{\dot{U}^{\prime}(C)}{U^{\prime}(C)}
\end{aligned}
$$

The associated system of prices $\left\{r_{t}^{*}, w_{t}^{*}, p_{E, t}^{*}, p_{F, t}^{*}, p_{B, t}^{*}, V_{H_{i}, t}^{*}\right\}_{t=0}^{\infty}$ is characterized by equations (2), (3), (4), (14), (16) and (21), respectively.

Proof. See Appendix A1.

A particular equilibrium is associated to a given quadruplet of policies $\left\{\sigma_{B, t}, \sigma_{E, t}, \sigma_{S, t}, \tau_{t}\right\}_{t=0}^{\infty}$ and the set of equations given by Proposition 1 allows to compute prices and quantities for this equilibrium. As we will see now, if the policy tools are set to their optimal levels, those equations also characterize the first-best optimum together with the system of prices that implements it.

\subsection{First-best optimum and implementation}

The social planner problem consists in choosing $\left\{C_{t}, Q_{B, t}, Q_{F, t}, Q_{S, t}, R_{B, t}, R_{E, t}, R_{S, t}\right\}_{t=0}^{\infty}$ that maximizes $W$, as defined by (26), subject to the output allocation constraint (30), the technological constraints (1), (5), (6), (10) and (15), the state equations (11), (20), (31), (32) and (33), and finally, the environmental damage constraints (34) and (35). 
After eliminating the co-state variables, the first-order conditions reduce to the seven characteristic conditions of Proposition 2 below.

Proposition 2 At each time t, an optimal solution is characterized by the following sevenequations system:

$$
\begin{aligned}
{\left[Q_{E} E_{F}-\frac{\left(\xi-S_{F}\right)}{S_{Q_{S}}}-\frac{1}{F_{Q_{F}}}\right] U^{\prime}(C) e^{-\rho t}+\int_{t}^{\infty} \frac{F_{Z}}{F_{Q_{F}}} U^{\prime}(C) e^{-\rho s} d s } & =0 \\
Q_{E} E_{B} B_{Q_{B}} & =1 \\
-\left(\zeta+\frac{S_{Q_{S}}}{S_{Q_{S}}}+\frac{S_{Q_{S}} \Phi^{\prime}(G)}{U^{\prime}(C)} \int_{t}^{\infty} Q_{\Omega} \Omega^{\prime}(T) U^{\prime}(C) e^{-(m+\rho)(s-t)} d s\right) & \leq \rho-\frac{\dot{U}^{\prime}(C)}{U^{\prime}(C)} \\
Q_{K}-\delta & =\rho-\frac{\dot{U}^{\prime}(C)}{U^{\prime}(C)} \\
H_{H_{B}}^{B}+\frac{H_{R_{B}}^{B} B_{H_{B}}}{B_{Q_{B}}}-\frac{\dot{H}_{R_{B}}^{B}}{H_{R_{B}}^{B}} & =\rho-\frac{\dot{U}^{\prime}(C)}{U^{\prime}(C)} \\
H_{H_{E}}^{E}+\frac{H_{R_{E}}^{E} E_{H_{E}}}{E_{B} B_{Q_{B}}}-\frac{\dot{H}_{R_{E}}^{E}}{H_{R_{E}}^{E}} & =\rho-\frac{\dot{U}^{\prime}(C)}{U^{\prime}(C)} \\
H_{H_{S}}^{S}+\frac{H_{R_{S}}^{S} S_{H_{S}}}{S_{Q_{S}}}-\frac{\dot{H}_{R_{S}}^{S}}{H_{R_{S}}^{S}} & =\rho-\frac{\dot{U}^{\prime}(C)}{U^{\prime}(C)}
\end{aligned}
$$

where (45) holds with equality as long as the atmospheric carbon concentration cap is not reached: $G_{t}<\bar{G}$.

Proof. See Appendix A2.

Equation (43) reads as a particular version of the Hotelling rule in this model, which takes into account the pollution caused by the fossil fuel use and the CCS option. Equation (44) tells that the marginal productivity of specific input $Q_{B, t}$ equals its marginal cost. Equation (45) equalizes the marginal benefit of sequestration and its marginal cost. In fact, the LHS of (45) denotes the marginal reduction in the social damage due to an increase of $Q_{S}, t$ by one unit, whereas the RHS is the corresponding marginal cost in term of utility loss (à reprendre). The four last equations are Keynes-Ramsey conditions. Equation (46) characterizes the optimal trade-off between physical capital $K_{t}$ and consumption $C_{t}$, as in more standard growth models. Equation (47) (resp. (48) and (49)) characterizes the same kind of optimal trade-off between specific investment into backstop R\&D sector, $R_{B, t}$ (resp. energy R\&D sector, $R_{E, t}$, and CCS R\&D sector, $R_{S, t}$ ) and consumption.

Recall that for a given set of public policies, a particular equilibrium is characterized by conditions (36)-(42) of Proposition 1. This equilibrium will be said to be optimal if 
it satisfies the optimum characterizing conditions (43)-(49) of Proposition 2. By analogy between these two sets of conditions, we can show that there exists a single quadruplet $\left\{\sigma_{B, t}, \sigma_{E, t}, \sigma_{S, t}, \tau_{t}\right\}_{t=0}^{\infty}$ that implements the optimum.

First, log-differentiating (38) and using (45), we find that dynamics of the optimal tax must satisfy the following condition:

$$
\frac{\dot{\tau}_{t}}{\tau_{t}} \leq \zeta+\rho-\frac{\dot{U}^{\prime}\left(C_{t}\right)}{U^{\prime}\left(C_{t}\right)}+\frac{S_{Q_{S}} \Phi^{\prime}(G)}{U^{\prime}\left(C_{t}\right)} \int_{t}^{\infty} Q_{\Omega} \Omega^{\prime}\left(T_{s}\right) U^{\prime}\left(C_{s}\right) e^{-(m+\rho)(s-t)} d s
$$

which holds with equality for any $t$ such that $G_{t}<\bar{G}$. Hence, as long as the atmospheric carbon concentration stays below the ceiling, the growth rate of the optimal tax is defined by the RHS of (50). Once the stabilization carbon cap is attained, the optimal tax grows at a lower rate and it can eventually become diminishing over time.

Without any loss of generality, assume that the optimal tax at date 0 is nil, then the solution of the differential equation (50) for any $t$ such that $G_{t}<\bar{G}$ is:

$$
\tau_{t}^{o}=-\frac{1}{U^{\prime}\left(C_{t}\right)}\left\{\int_{t}^{\infty}\left[\int_{s}^{\infty} Q_{\Omega} \Omega^{\prime}\left(T_{x}\right) U^{\prime}\left(C_{x}\right) e^{-(m+\rho)(x-s)} d x\right] \Phi^{\prime}\left(G_{s}\right) e^{-(\zeta+\rho)(s-t)} d s\right\}
$$

which is positive since $\Omega^{\prime}(T)<0$. This expression reads as the ratio between the marginal social cost of climate change - the marginal damage in terms of utility coming from the emission of an additional unit of carbon - and the marginal utility of consumption. In other words, it is the environmental cost of one unit of carbon in terms of final good.

Finally, the correspondence between the equilibrium characterizing condition (40) (resp. (41) and (42)) and the optimum characterizing condition (47) (resp. (48) and (49)) is achieved if and only if $\sigma_{i, t}$ is equal to $1-\gamma_{i}, i=\{B, E, S\}$, i.e. if the three sectors are fully subsidized. All the remaining conditions of the two sets are equivalent. These findings are summarized in Proposition 3 below.

Proposition 3 The equilibrium defined in Proposition 1 is optimal if and only if the quadruplet of policies $\left\{\sigma_{B, t}, \sigma_{E, t}, \sigma_{S, t}, \tau_{t}\right\}_{t=0}^{\infty}$ is such that $\sigma_{B, t}=1-\gamma_{B}, \sigma_{E, t}=1-\gamma_{E}$, $\sigma_{S, t}=1-\gamma_{S}$ and $\tau_{t}=\tau_{t}^{o}$, for all $t \geq 0$ such that $G_{t}<\bar{G}$.

\section{Numerical results}

Since the previous version of the numerical model (see Grimaud et al., 2007), the model has been upgraded so as to fine-tune the baseline case according to the latest adjustments 
made to the DICE model (Nordhaus, 2007b). The climate module, demographic dynamics and the feedbacks on economic productivity from climate change have notably been revised. The starting year is now the year 2005, which required the update of initial values for all variables. The total factor productivity has been adjusted so as to produce a similar pattern of GWP development until 2100 to the one from DICE 2007. The second enhancement consisted in incorporating the CCS technology in the model. For this matter, we used a similar specification to the DEMETER model (Gerlagh and van der Zwaan, 2006). Remaining functional forms have been discussed in Grimaud et al. (2007) and are kept unchanged. Calibration details are described in Appendix A3.

To study numerically the effect of policy instruments on the decentralized equilibrium, we first run the benchmark case in which neither environmental tax nor R\&D subsidies are implemented, i.e. the "laisser-faire" case. Next, we solve the equilibrium for various values of $\tau_{t}$ and $\sigma_{i}, i=\{B, E, S\}$. The selected cases are listed in the following table.

\begin{tabular}{cccccl}
\hline \hline Case & $\tau_{t}$ & $\sigma_{E}$ & $\sigma_{B}$ & $\sigma_{S}$ & Comment \\
\hline$A$ & 0 & 0 & 0 & 0 & Laisser-faire \\
$B$ & $\tau_{t}^{o}$ & 0 & 0 & 0 & Optimal tax, no R\&D subsidy \\
$C$ & 0 & $1-\gamma_{E}$ & $1-\gamma_{B}$ & $1-\gamma_{S}$ & Optimal subsidies, no tax \\
$D$ & $\tau_{t}^{o}$ & $1-\gamma_{E}$ & $1-\gamma_{B}$ & $1-\gamma_{S}$ & First-best optimum (w/o ceiling) \\
$E$ & $\tau_{t}^{550}$ & $1-\gamma_{E}$ & $1-\gamma_{B}$ & $1-\gamma_{S}$ & Optimum with a 550ppm ceiling \\
$F$ & $\tau_{t}^{450}$ & $1-\gamma_{E}$ & $1-\gamma_{B}$ & $1-\gamma_{S}$ & Optimum with a 450ppm ceiling \\
$G$ & $\tau_{t}^{550}$ & $1-\gamma_{E}$ & $1-\gamma_{B}$ & 0 & Backstop subs. effect when $\tau_{t}=\tau_{t}^{550}$ \\
$H$ & $\tau_{t}^{550}$ & $1-\gamma_{E}$ & 0 & $1-\gamma_{S}$ & CCS subs. effect when $\tau_{t}=\tau_{t}^{550}$ \\
$I$ & $\tau_{t}^{450}$ & $1-\gamma_{E}$ & $1-\gamma_{B}$ & 0 & Backstop subs. effect when $\tau_{t}=\tau_{t}^{450}$ \\
$J$ & $\tau_{t}^{450}$ & $1-\gamma_{E}$ & 0 & $1-\gamma_{S}$ & CCS subs. effect when $\tau_{t}=\tau_{t}^{450}$ \\
\hline & & & & & \\
\hline
\end{tabular}

Table 1: Summary of the various cases

Case $A$ refers as the laisser-faire equilibrium. We study the effect on the equilibrium of an environmental tax, for instance by setting it equal to its first-best optimal level $\tau^{o}$ (case $B)$. Similarly, we analyze the impact of optimal R\&D subsidies in case $C$. When all the instruments are set equal to their optimal levels (cf. Proposition 3), we restore the first- 
best optimum without ceiling on carbon concentration (case $D$ ). Two stabilization levels of 450 and 550ppm are also studied. Those two runs (referred to as "Optimum450" and "Optimum550") will also serve as benchmarks and will help us identifying the conditions under which sufficient level of R\&D in backstop and CCS expenses necessary to bring the CCS technology to the market (cases G, H, I and J). Cases $D, E$ and $F$ are obtained from the optimum program (cf. section 3.2), whereas cases $A, B, C$ and $G-J$ are run from the equilibrium model.

The optimal tax levels required for the restoration of first-best optimum and the stabilization of carbon atmospheric carbon are depicted in Figure 2. The first-best tax level starts from a $49 \$ / \mathrm{tC}$ and follows an quasi-linear increase to reach $256 \$ / \mathrm{tC}$ by 2100 . The stabilization to 550 and 450 requires much higher tax levels: Starting from respectively 73 and $172 \$ / \mathrm{tC}$, they increase sharply, reach some high $550 \$ / \mathrm{tC}$ and $735 \$ / \mathrm{tC}$ in 2075 and 2055, before declining once the concentration ceiling has been reached. Naturally, the rate of increase of the carbon prices for the 450ppm target is more rapid than that of the $550 \mathrm{ppm}$ case. Those carbon prices prove slightly higher than Nordhaus (2007b) estimates for similar climate strategies.

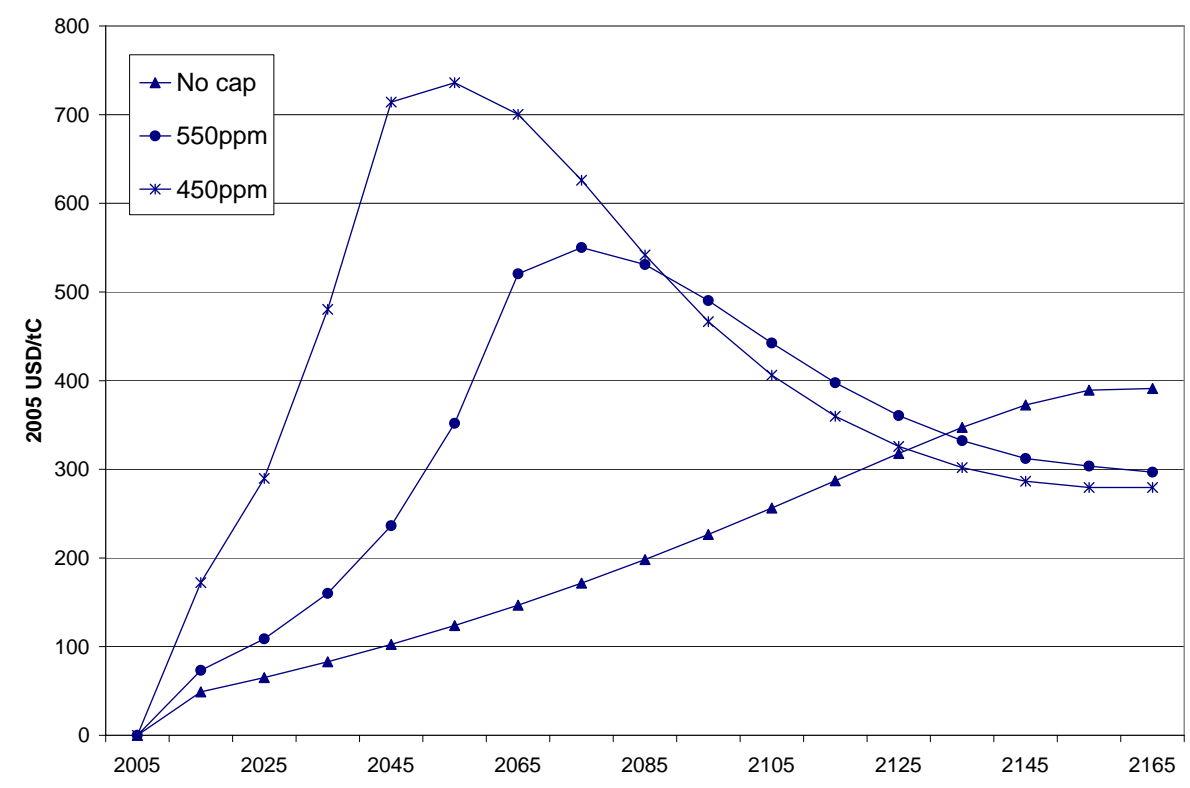

Figure 2: Optimal environmental taxes

The effects of directed technical change can be portrayed by examining the market value of an innovation in both CCS and backstop R\&D, as depicted in the upper panels 
of Figure 3. The corresponding knowledge accumulation is provided is the lower panels of Figure 3.

The behavior of those innovation prices provide insights on the allocation and the direction of R\&D funding over time. First, the rising prices demonstrate that the innovation market grows strongly during the century, with the exception of the laisser-faire case which does not provide incentive for investing in CCS, as will be confirmed later. Second, the increase in innovation prices is strongly governed by the stringency of climate policy. Clearly, the introduction of a carbon ceiling induces the fastest increase in the market value of innovations. Third, the role of each mitigation option can be inferred from the time-path of both CCS and backstop innovations: CCS innovation grows fast from the earliest periods, reaches a peak by around 2075 and stars declining thereafter. On the contrary, the backstop innovation price keeps on rising over time, though at a slow pace initially. A simple supply-demand argument is necessary to understand those behaviors. As the innovation market is growing fast, due to the urgent need of developing carbon-free energy supply, and as the expected returns on CCS R\&D are the highest initially because of relatively low cost of technology improvement relative to the backstop, a "technology push" in favor of CCS cause its innovation price to rise fast. In the longer run, backstop energy offers larger market and deployment potential and thus takes over CCS investments. Its price then develops at a faster pace while the CCS innovation is becoming less valued as its market shrinks.

Those innovation prices drive the $R \& D$ expenses flowing to each research sector. Figure 3 depicts such R\&D budgets for our major cases. The first-best optimum restoration calls for a continuous increase in R\&D budgets that will mainly benefit the development of the backstop technology. By the end of the century, overall R\&D budgets will then have been multiplied by a factor of roughly 10, amounting to slightly less than 1 billion USD. The energy efficiency sector and the CCS sector receive respectively 13 and $17 \%$ of total R\&D budgets in 2100. In the polar laisser-faire case, hardly any $R \& D$ budget is dedicated to research. CCS R\&D is not financed at all. A similar outcome occurs when an optimal tax is set while research subsidies are nil (upper-right panel from Figure). On the contrary, when all research subsidies are optimally set without carbon tax, R\&D allowances do not profit the CCS sector but mainly the backstop research sector that receives similar amounts to the first-best optimal case. Looking at the two stabilization cases, one notices drastic changes in $R \& D$ budgets allocation and volumes. By the end of century, the overall $R \& D$ 

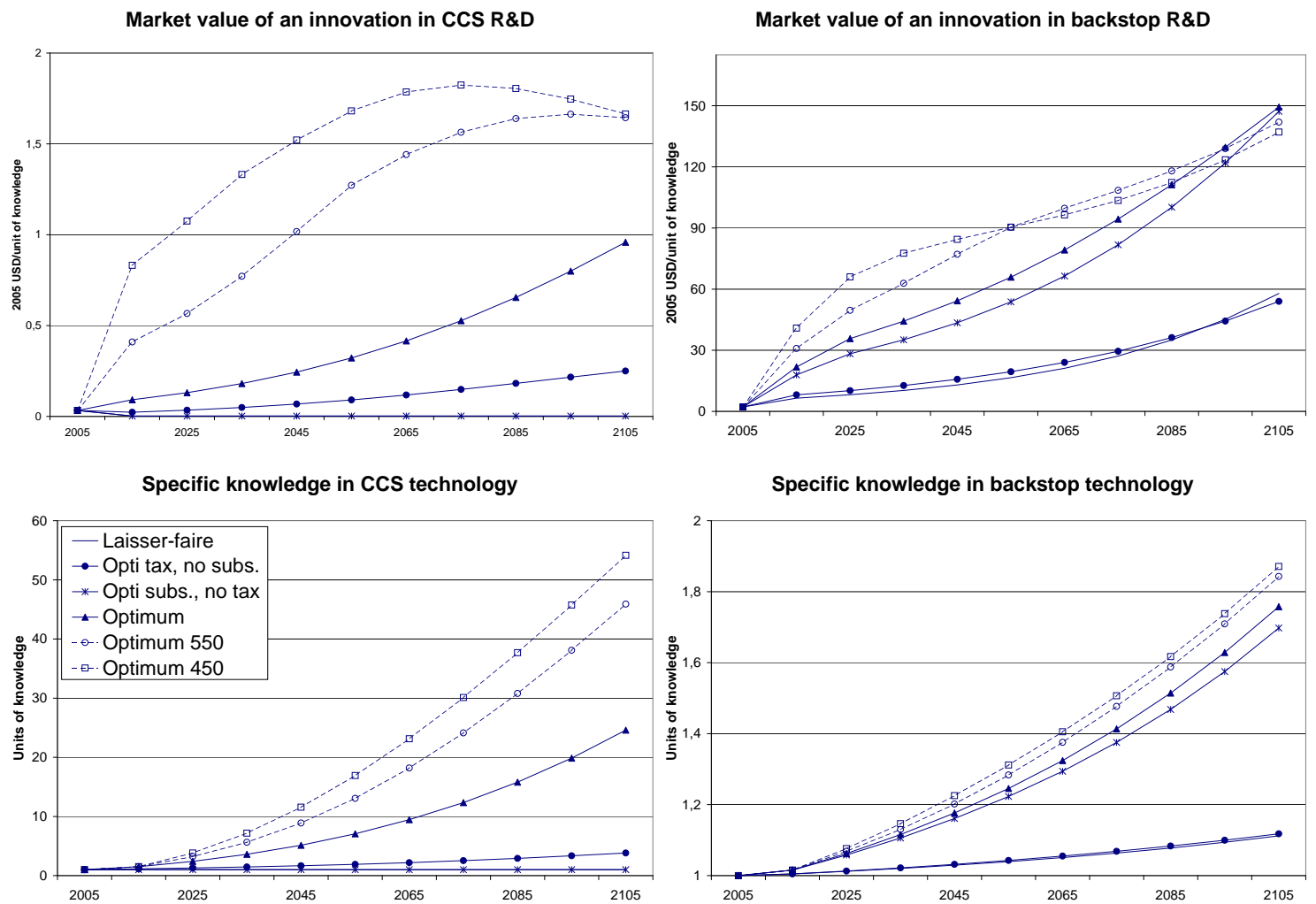

Figure 3: Innovation market value and specific knowledge accumulation

budgets exceed the ones obtained when restoring the first-best solution. The necessity of curbing quickly the net polluting emissions flow leads to substantial investments in CCS $\mathrm{R} \& \mathrm{D}$ that constitutes the cheapest mid-term mitigation option. The more stringent the carbon target, the higher is the share of CCS R\&D spending.

Two conclusions can be drawn so far. The implementation a carbon tax alone hardly provides any incentive to proceed with $R \& D$ activities. In order to provide enough $R \& D$ incentives, one needs first to correct for the externality by imposing a carbon tax and second by subsidizing the research sectors. Moreover, short term investment in carbon-free technology, namely in CCS activities, can become relevant when imposing a stringent cap on carbon accumulation, or equivalently, an higher level of tax.

Before investigating how the encouragement of $R \& D$ enhances the market penetration of alternative carbon-free energy sources, let us give some attention to the joint development of energy prices. The fossil fuel market price increase only slowly due to the relative flatness of our fossil fuel supply curve (see Figure 5, Left panel). As previously noticed by Grimaud et al. (2007), the implementation of a carbon tax reduces the producer price 
A) Laisser-faire

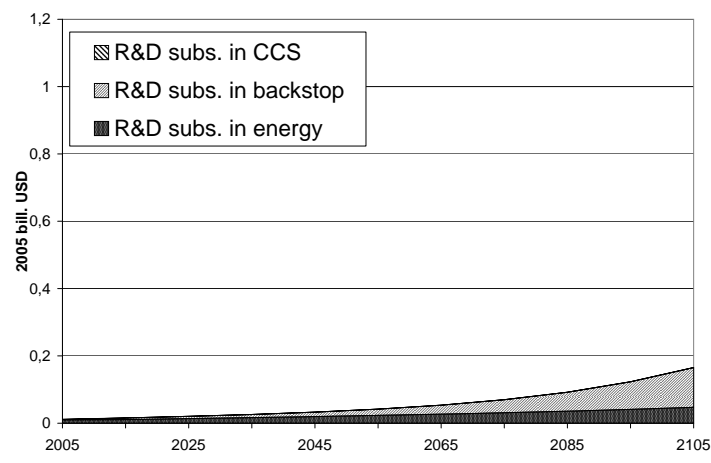

C) Optimal R\&D subsidies, no tax

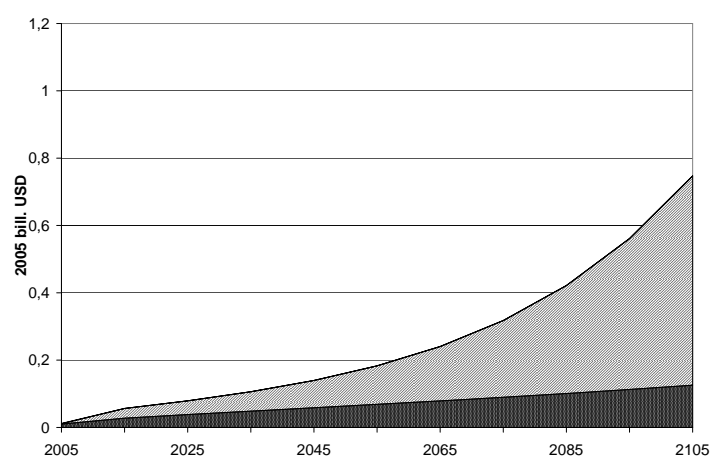

E) Optimum 550ppm

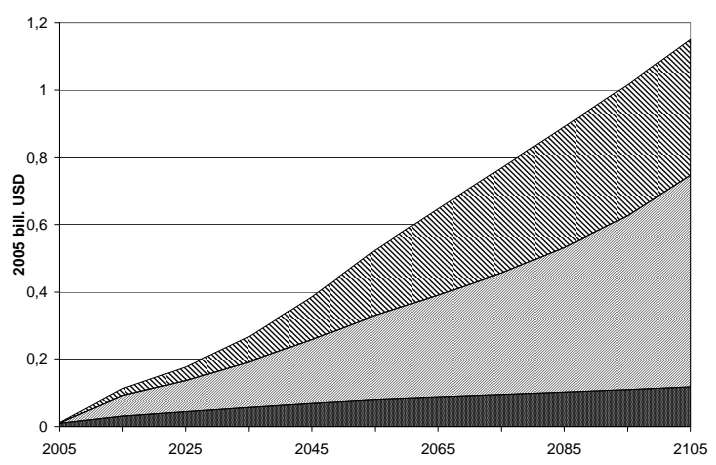

B) Optimal tax, no R\&D subsidies

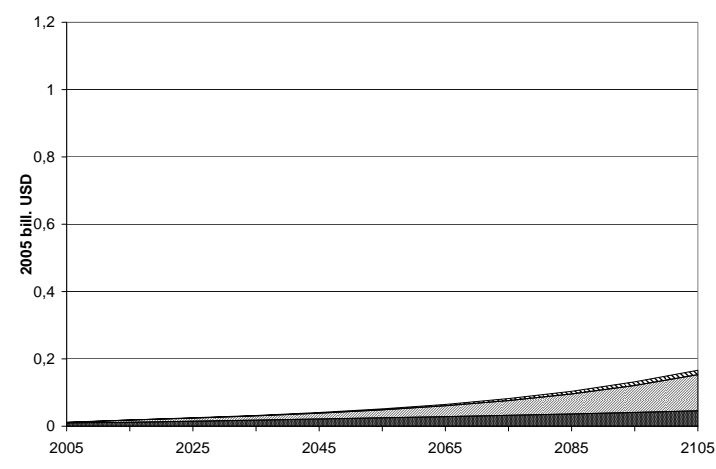

D) First-best optimum

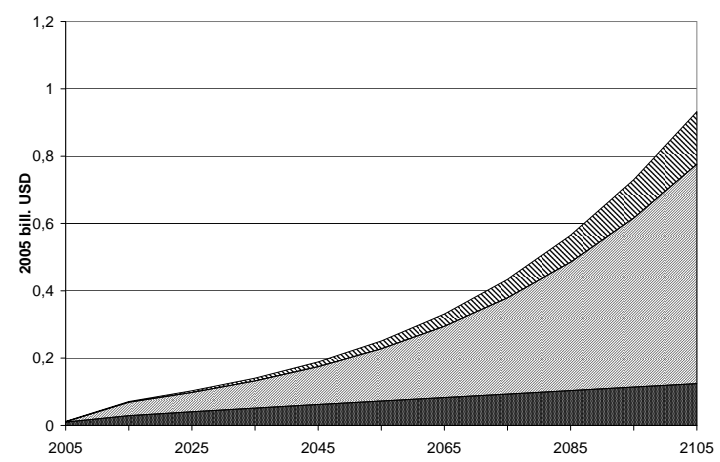

F) Optimum 450ppm

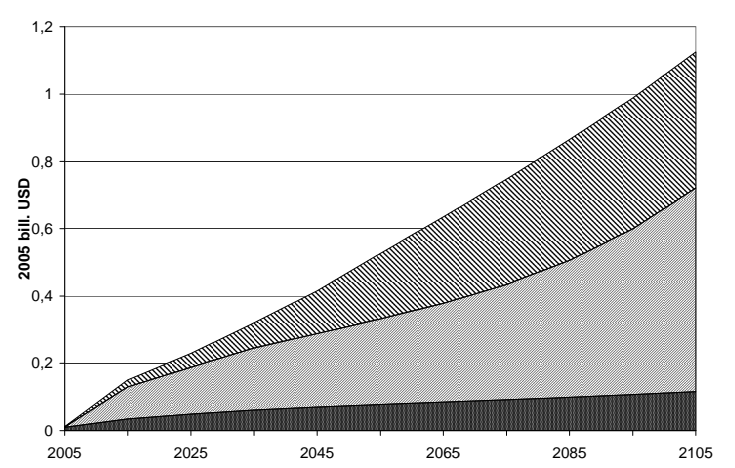

Figure 4: Dedicated R\&D investments 
which induces substantial rent transfers from extractive industries to governments. In 2105 , the revenues losses for the fossil energy producer amount to $55 \%$ and $52 \%$ when carbon caps are set at 550 and 450ppm, respectively. The concerns of oil-rich countries towards stringent climate mitigation commitments has already been commented and assessed in the literature (see for example REFs). The decreasing market price of the backstop energy reveals largely affected by the introduction of research subsidies, as can be seen from Figure 5 (Right panel). Such subsidies stimulate backstop research, thereby increasing its productivity and then, reducing production cost. They allow the backstop price to be cut by half by 2105 .

Moreover, the ratio of the fossil fuel and backstop productivities, given by equation (7) and (8), equals the ratio of the full marginal cost of using fossil energy (i.e. including the cost of carbon adjusted for CCS development) to the backstop marginal cost. This technical rate of substitution (TRS), provided by Figure 6, is increasing over time and shows how each unit of fossil resource will progressively be replaced by more and more backstop energy. This is possible because the fall in backstop price more than compensates the strong reduction of the carbon tax once the ceiling has been reached.
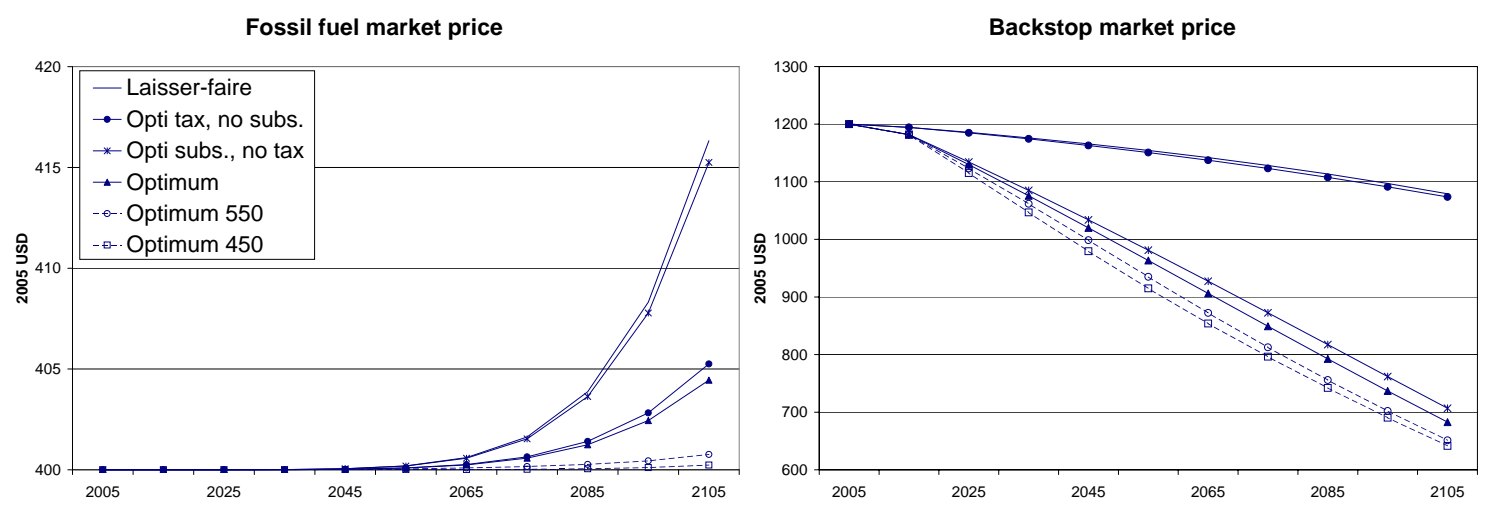

Figure 5: Primary energy prices

Let us now turn to the development of primary energy use throughout the century. As seen from Figure 7, the laisser-faire case induces a five-fold increase in energy use over the century, driven by strong economic growth and the absence of policy restrictions. No CCS $\mathrm{R} \& \mathrm{D}$ are incurred in this case, and the CCS technology remains non competitive and is not utilized at all. The implementation of all optimal instruments leads to a lower 4 -fold increase in energy use by 2100 . Owing to dedicated R\&D subsidies, technical improvement 


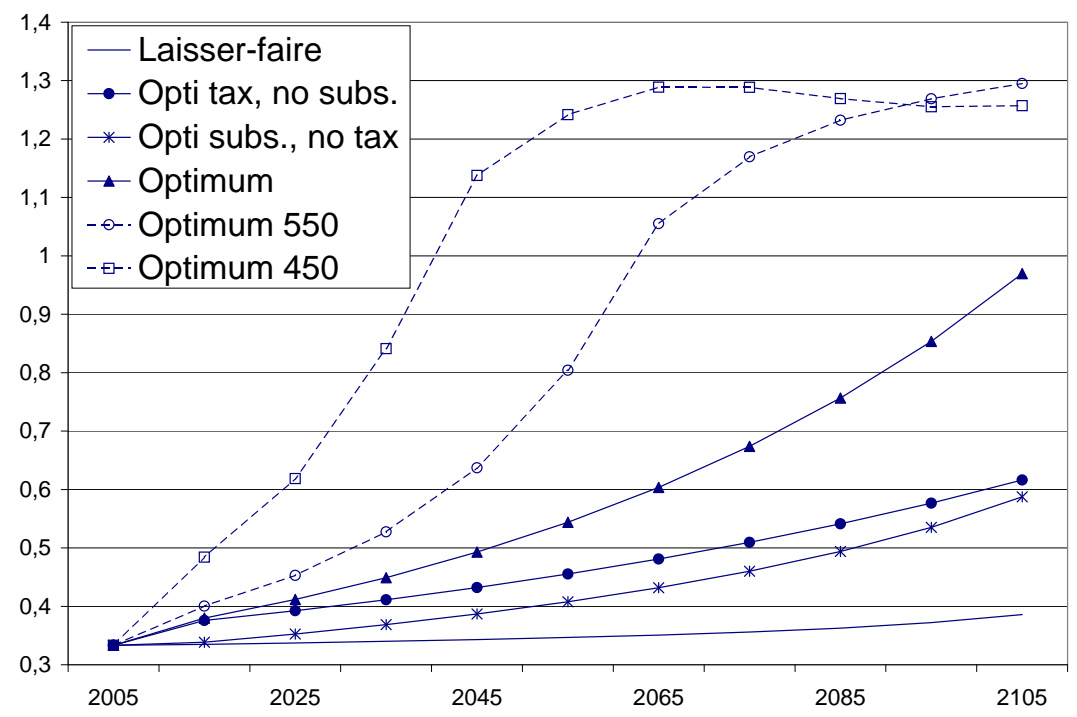

Figure 6: Technical rate of substitution (TRS) of backstop for fossil fuel

in the CCS sector is sufficient to bring the cost of carbon removal down so that an increasing fraction of carbon emissions are effectively sequestered. Displaced carbon represents $14 \%$ of total carbon emissions in 2100. Intermediate cases where either the tax or the R\&D subsidies are implemented do not result in substantial carbon sequestration. Rather, the two stabilization cases induce radical changes in world energy supply. The sharp increase of carbon prices result in strong reductions of energy use especially in the short-term where substitution possibilities with carbon-free energy are not yet available. In the $550 \mathrm{ppm}$ case, energy demand will have been reduced by $47 \%$ and by $60 \%$ by 2050 . In addition, the large amounts of $R \& D$ budgets allocated to carbon-free research produce the expected benefits and allow for a deep mitigation of climate change owing to the decarbonization of the economy both via the massive introduction of carbon-free fossil fuel use and via the backstop. When those carbon-free alternatives become economical, energy use rises again to reach similar levels to the laisser-faire ones in 2100. By that time, the backstop energy supplies $46 \%$ and $42 \%$ of total energy consumption. In the 550 and $450 \mathrm{ppm}$ cases, the CCS-based fossil fuel use accounts for $40 \%$ and $49 \%$ of total energy use in the 550 and $450 \mathrm{ppm}$ cases respectively. Therefore the lower the carbon target, the higher is the share of emission-free fossil fuel use.

The environmental consequences of alternatives scenarios are represented in Figure 8. The implementation of optimal instruments leads to a increase of atmospheric carbon 
A) Laisser-faire

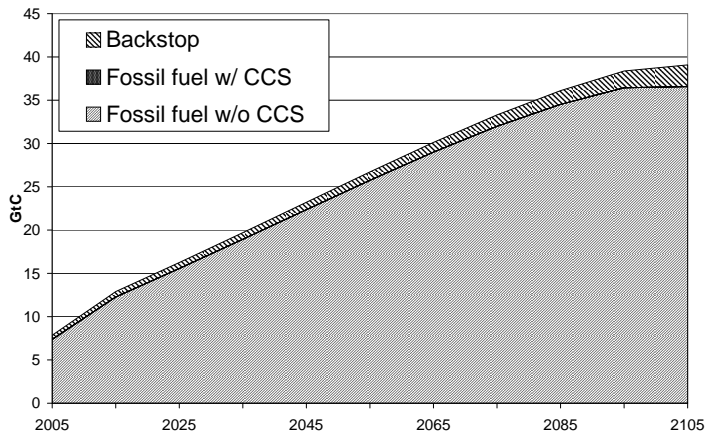

C) Optimal R\&D subsidies, no tax

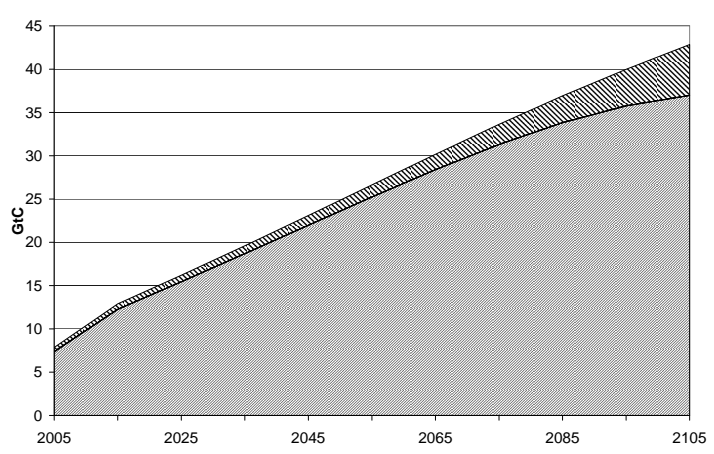

E) Optimum 550ppm

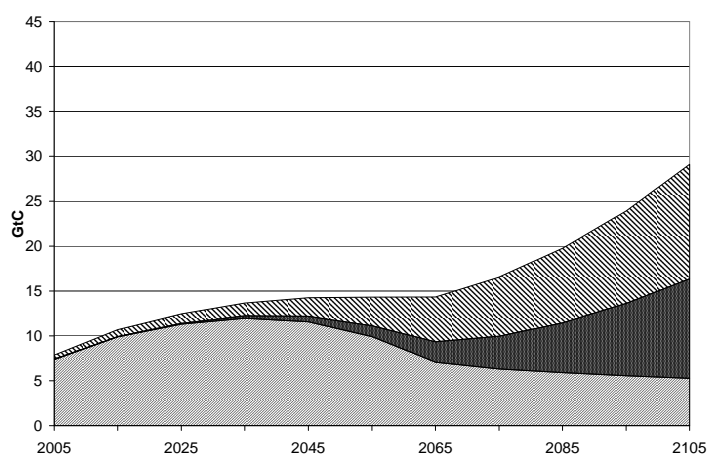

B) Optimal tax, no R\&D subsidies

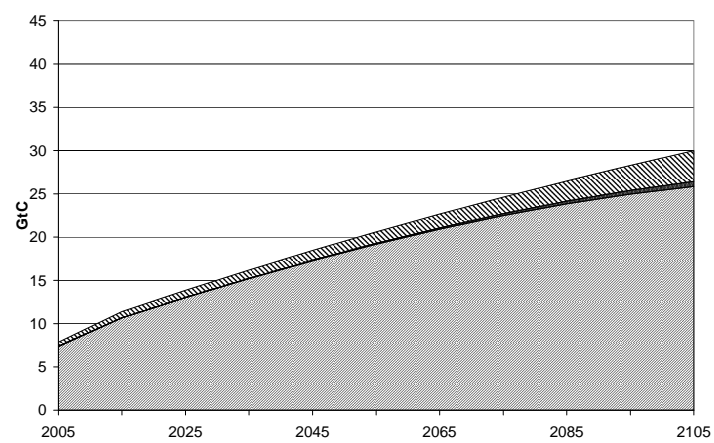

D) First-best optimum

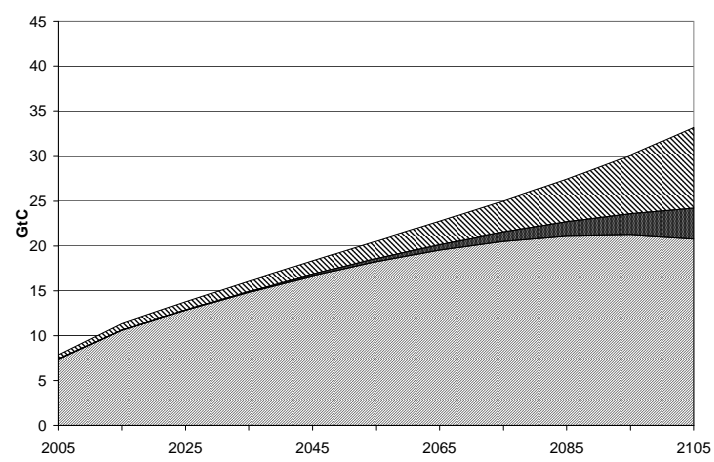

F) Optimum 450ppm

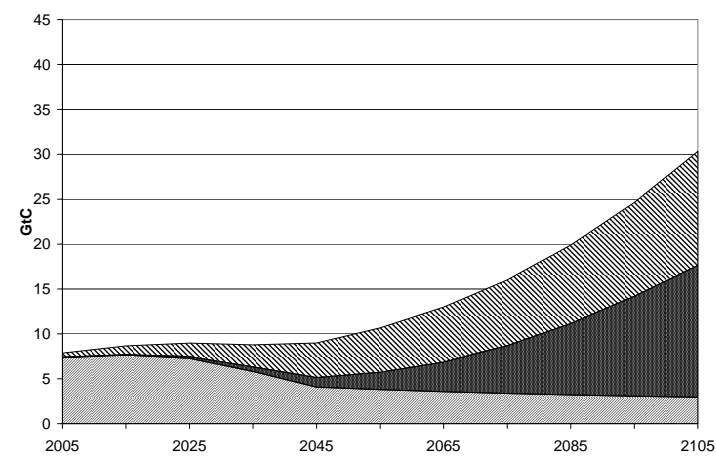

Figure 7: Primary energy use 
accumulation up to $800 \mathrm{ppm}$ by 2100 . The implementation of the sole optimal tax without further R\&D subsidies leads a slightly higher level of $850 \mathrm{ppm}$. The decentralized market outcome without any policy intervention involves a more intensive energy use without CO2 removal and thus a faster carbon accumulation above to some dangerous 1000ppm level (IPCC, 2007). Notice that the sole optimal subsidies without $\mathrm{CO}_{2}$ pricing just prove as inefficient from the environmental point of view.
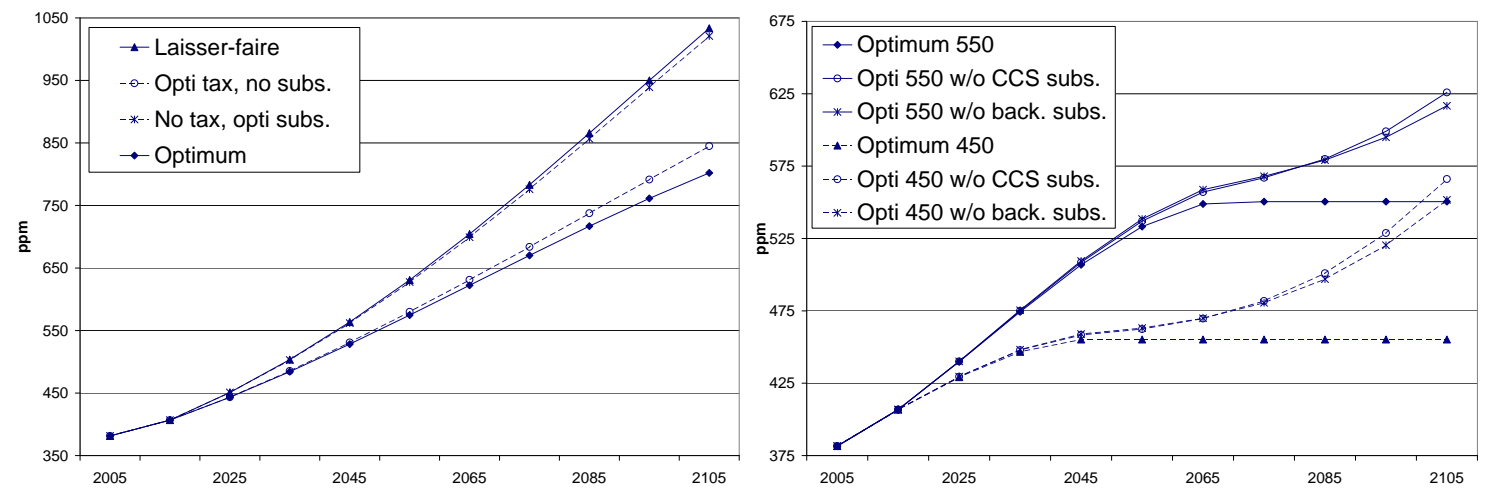

Figure 8: Atmospheric carbon concentration

Additionally, results depicted in the right panel of Figure 8 clearly demonstrate how important the subsidies become to both CCS and backstop research sectors when a cap on carbon accumulation is set. We have seen that subsidies flow massively to each sector by the middle of the century when the climate change adverse effects need to be urgently mitigated. Therefore removing those research incentives induce a departure of carbon concentration from their optimal counterparts by 2055 and 2045 in the respective cases of 550 and $450 \mathrm{ppm}$ targets. The insufficient market incentives to the private sectors conduct the carbon concentration to overshoot its target and reaches 630 and $570 \mathrm{ppm}$ by 2100 , instead of the respective 550 and 450 caps.

Those various climate policies strongly affect Gross World Product. The Figure 9 gives the GWP time-development as a percentage of the one from the laisser-faire case. The sole implementation of optimal subsidies improves the GWP, and provides an increase of up to $4 \%$ above the Laisser-Faire case by 2145 (Figure 9, left panel). The implementation of the optimal tax alone reveal costly until the end of the century. The reduction in fossil energy consumption is less than compensated by the increase in backstop energy use, whose cost remains too high due to insufficient technological improvements. More importantly, 
setting economic instruments to their optimal values leads to further GWP losses in the short and mid term compared to the market outcome without intervention. In the longer run though, GWP increases significantly again and catches up the laisser-faire trajectory by 2095 , to reach even higher gains eventually (Case), up to $8 \%$ in 2145 . Note that Stern (2006) reported much higher GDP losses, in the range of $20 \%$, in the case of no policy intervention.

Those behaviors confirm that investing in $R \& D$ and reducing the fossil energy use without $\mathrm{CO} 2$ removal, however costly it might be in the coming future, does provide the expected long term returns. The long run economic growth is thus always enhanced when climate change issue is addressed with the appropriate tools. In addition, the sole carbon tax proves very costly and cannot solve the climate change problem alone. On another hand, research funding efficiently accelerates the introduction of carbon-free energy and does not hinder economic growth.

When the atmospheric carbon accumulation is kept below some threshold, mid term GWP losses are more substantial, down to $4 \%$ and $6 \%$ according to the target (see Figure 9 , right panel). No matter which instrument is removed or used, similar patterns can be observed across the various cases.
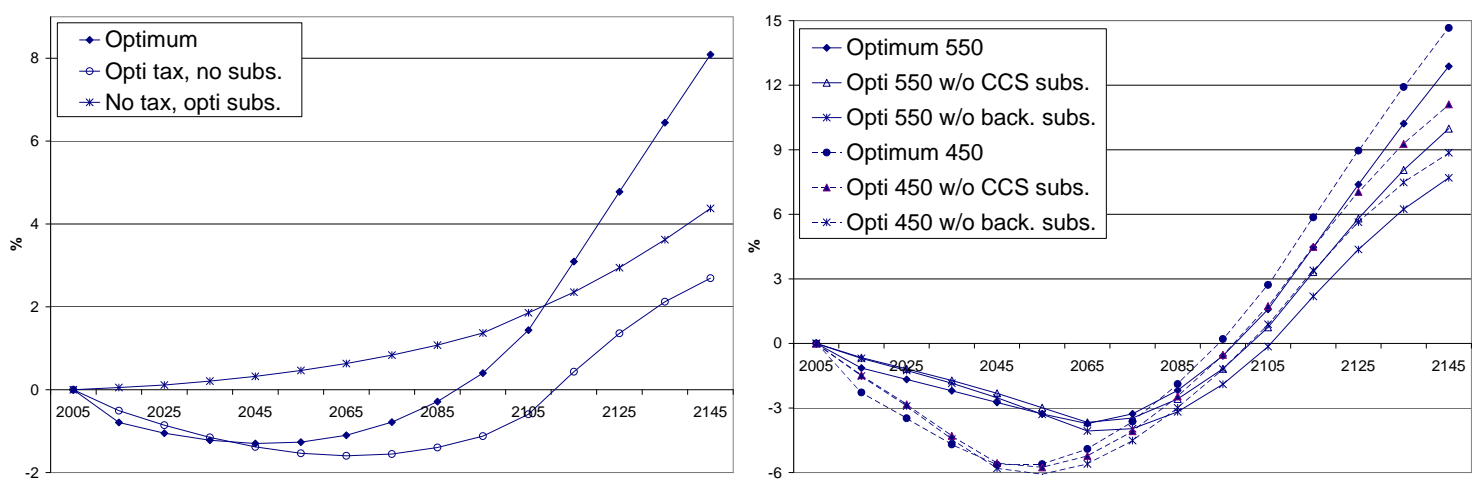

Figure 9: GWP variations (in \%) as compared with the LF case

Finally, Figure 10 gives a better sense of the overall (and discounted) effects of the various policies on welfare variations. The restoration of the first outcome leads to the highest welfare improvement, followed by the case where appropriate research subsidies are made. Interestingly, the 550ppm carbon cap still provides overall benefits, the long run avoided damages more than compensating the mid-term policy cost. The $450 \mathrm{ppm}$ 
turns out very expensive and always translates into overall welfare variations in the range of half a percent, but this is perhaps lower than the welfare cost induced by catastrophic and irreversible events that are supposed to be taken into account by such a cap. This shows how difficult it is to achieve such a low target.

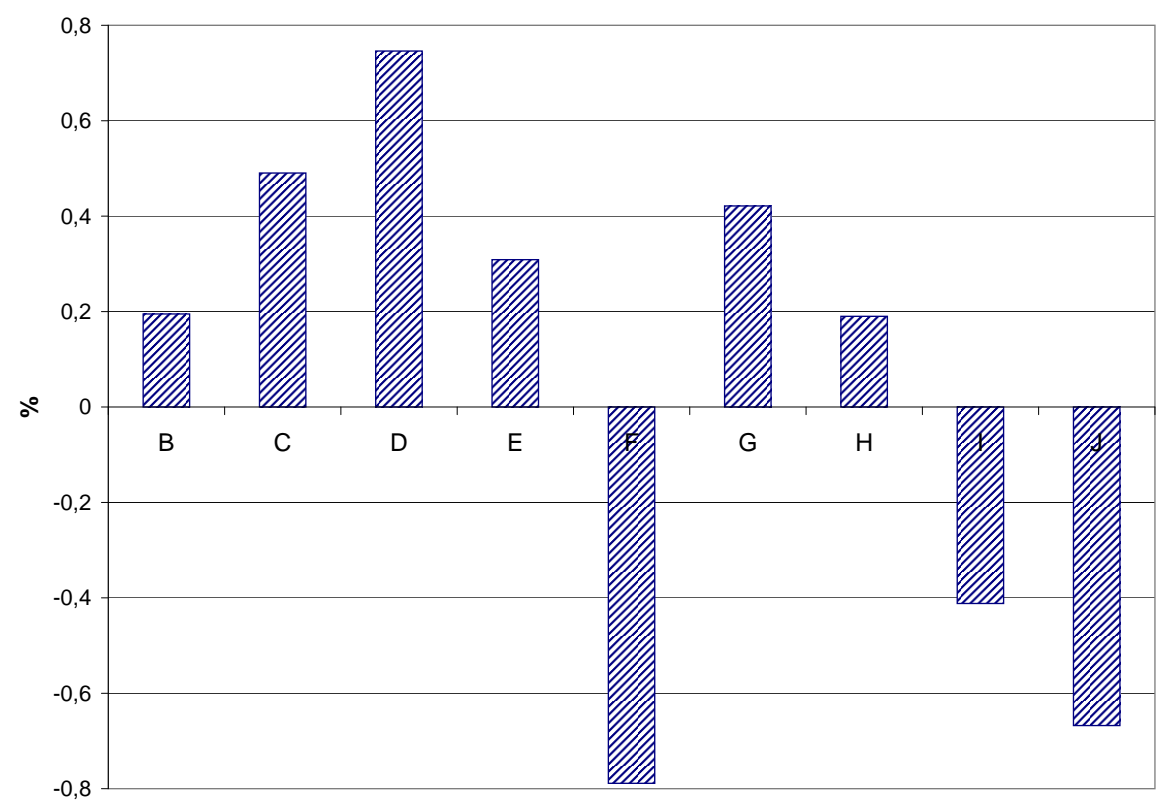

Figure 10: Welfare variations (in \%) of various cases as compared with the LF case

\section{Conclusion}

Our analysis consisted first in developing the analytical foundations of an economic growth model that takes into account the harmful effects of climate change, along with the possibility to improve the productivity of climate mitigation options, namely energy efficiency, carbon capture and renewable energy, through directed R\&D efforts. Our framework allows assessing how effective alternative policy scenarios are as compared with the market, or laisser-faire, outcome. This explicit comparison is based on the implementation of two kinds of policy instruments: a carbon tax and directed research subsidies. In a second step, we use a calibrated version of the theoretical model to assess the environmental and economic impacts of various climate change policies. In addition, and in order to account for further climate change damages that are not integrated in our damage function (i.e. the one from Nordhaus's DICE 2007 model), we imposed a cap on the atmospheric carbon accumulation. We find that i) the implementation of optimal instruments restores the 
first-best outcome. ii) Intermediate cases where either the tax or the R\&D subsidies are implemented do not result in substantial carbon sequestration. iii) The implementation a carbon tax alone hardly provides any incentive to proceed with R\&D activities. iv) When a carbon cap is imposed, subsidizing the research sectors of both the CCS and the backstop reveals to be a key mechanism in order to bring the policy costs down and do not hinder economic growth too much. The cap reinforces the role of CCS as a mid-term option for mitigating the climate change. In the longer term, if the policy-maker aims at stabilizing the climate, the massive introduction of backstop is necessary. This becomes possible by redirecting subsidies from the CCS research sector to the backstop sector. Imposing a $550 \mathrm{ppm}$ target does result in an overall welfare improvement, in the order of $0.3 \%$, contrary to a very stringent $450 \mathrm{ppm}$ that results in net welfare losses of around $0.5 \%$, as compared to the laisser-faire case. Finally, removing research subsidies prevents from meeting any stabilization target, which is then already overshot by the middle of century.

\section{References}

[1] Acemoglu, D., 2002. Directed technical change. Review of Economic Studies 69(4), 781-809.

[2] Aghion, P., Howitt, P., 1998. Endogenous growth theory. Cambridge, MA: MIT Press.

[3] Bosetti, V., Carraro, C., Graleotti, M., 2006. The dynamics of carbon and energy intensity in a model of endogenous technical change. The Energy Journal, Special issue, 191-206.

[4] Chakravorty, U., Magné, B., Moreaux, M., 2006. A Hotelling model with a ceiling on the stock of pollution, Journal of Economic Dynamics and Control 30, 2875-2904.

[5] Edenhofer, O., Bauer, N., Kriegler, E., 2005. The impact of technological change on climate protection and welfare: Insights from the model MIND. Ecological Economics $54,277-292$.

[6] Edenhofer, O., Lessman, K., Bauer, N., 2006. Mitigation strategies ans costs of climate protection: The effects of ETC in the hybrid model MIND. The Energy Journal, Special issue, 207-222.

[7] Farzin, Y.H., Tahvonen, O., 1996. Global carbon cycle and the optimal time path of carbon tax. Oxford Economic Papers 48, 515-536. 
[8] Fischer, C., Parry, I., Pizer, W.A., 2003. Instrument choice for environmental protection when technological innovation is endogenous. Journal of Environmental Economics and Management 45, 523-545.

[9] Gerlagh, R., Lise, W., 2005. Carbon taxes: A drop in the ocean, or a drop that erodes the stone? The effect of carbon taxes on technological change. Ecological Economics $54,241-260$.

[10] Gerlagh, R., 2006. ITC in a global growth-climate model with CCS: The value of induced technical change for climate stabilization. The Energy Journal, Special issue, 223-240.

[11] Gerlagh, R., van der Zwaan, B.C.C., 2006. Options and instruments for a deep cut in $\mathrm{CO}_{2}$ emissions: Carbon capture or renewables, taxes or subsidies? The Energy Journal 27, 25-48.

[12] Goulder, L.H., Mathai, K. 2000. Optimal $\mathrm{CO}_{2}$ abatement in the presence of induced technological change. Journal of Environmental Economics and Management 39, 1-38.

[13] Grimaud, A., Tournemaine, F., 2007. Why can an environmental policy tax promote growth through the channel of education? Ecological Economics 62(1), 27-36.

[14] Grimaud, A., Lafforgue, G., Magné, B., 2007. Decentralized equilibrium analysis in a growth model with directed technical progress and climate change mitigation, mimeo LERNA, Toulouse School of Economics.

[15] Grimaud, A., Rougé, L., 2008. Environment, directed technical change and economic policy. Forthcoming in Environmental and Resource Economics.

[16] Hart, R., 2007. The timing of taxes on $\mathrm{CO}_{2}$ emissions when technological change is endogenous. Journal of Environmental Economics and Management, forthcoming.

[17] Hoffert, M., et al. 2002. Advanced technology paths to global climate stability: Energy for a greenhouse planet. Science 298, 981-987.

[18] International Energy Agency (IEA), 2006. Energy Technology Perspectives, IEA Publications, Paris.

[19] International Energy Agency (IEA), 2007 
[20] Jones, C.I., 1995. R\&D-based models of economic growth. Journal of Political Economy 105, 759-784.

[21] Jones, C.I., Williams, J.C., 1998. Measuring the social return to R\&D. The Quarterly Journal of Economics 113(4), 119-1135.

[22] Jones, C.I, Williams, J.C., 2000. Too much of a good thing? The economics of investment in R\&D. Journal of Economic Growth 5(1), 65-85.

[23] Keller, K., McInerney, D., Bradford, D.F., 2008. Carbon dioxide sequestration: how much and when? Climatic Change, doi:10.1007/s10584-008-9417-x.

[24] Kolstad, C.D., Toman, M. 2001. The economics of climate policy. Resources For the Future, Discussion Paper n\#00.40REV.

[25] Kriegler, E., Bruckner, T., 2004. Sensitivity analysis of emissions corridors for the $21^{\text {st }}$ century. Climatic change 66, 345-387.

[26] Lafforgue, G., Magné, B., Moreaux, M., 2008. Energy substitutions, climate change and carbon sinks. Ecological Economics, doi:10.1016/j.ecolecon.2008.01.008.

[27] Nemet, G.F., Kammen, D.M., 2007. U.S. energy research and development: Declining investment, increasing need, and the feasibility of expansion. Energy Policy 35(1), $746-55$.

[28] Nordhaus, W.D., Boyer, J., 2000. Warming the world: Economic models of global warming. Cambridge, MA: MIT Press.

[29] Nordhaus, W.D., 2006. After Kyoto: Alternative mechanisms to control global warming. American Economic Review 96(2), 31-4.

[30] Nordhaus, W.D., 2007a. A Review of the Stern Review on the Economics of Global Warming. Journal of Economic Literature, forthcoming.

[31] Nordhaus, W.D., 2007b. The challenge of global warming: Economic models and environmental policy. Available at http://nordhaus.econ.yale.edu/.

[32] Popp, D., 2004. ENTICE: Endogenous technological change in the DICE model of global warming. Journal of Environmental Economics and Management 48, 742-768.

[33] Popp, D., 2006a. ENTICE-BR: The effects of backstop technology R\&D on climate policy models. Energy Economics 28, 188-222. 
[34] Popp, D., 2006b. Comparison of climate policies in the ENTICE-BR model. The Energy Journal, Special issue, 163-174.

[35] Quah, D.T., 2001. The weightless economy in economic development. In M. Pohjola (Ed.), Information technology, productivity and economic growth: International evidence. Oxford: Oxford University Press.

[36] Romer, P.M., 1990. Endogenous technical change. Journal of Political Economy 98(5), 71-102.

[37] Scotchmer, S., 2005. Innovations and incentives. Cambridge, MA: MIT Press. 


\section{Appendix}

\section{A1. Proof of Proposition 1}

Integrating (13) and using (12) and the transversality condition on $Z_{t}$, we find:

$$
\eta_{t}=\int_{t}^{\infty} \frac{F_{Z}}{F_{Q_{F}}} e^{-\int_{0}^{s} r_{x} d x} d s
$$

Then, the first characterizing condition (36) is obtained by replacing $\eta$ into (12) by the expression above, by noting that $p_{F}=Q_{E} E_{F}-\left(\xi-S_{F}\right) / S_{Q_{S}}$ from (4), (7) and (9), and that $\exp \left(-\int_{0}^{t} r d s\right)=U^{\prime}(C) \exp (-\rho t) / U^{\prime}\left(C_{0}\right)$ from (28). Combining (4), (8) and (16) leads to condition (37). Condition (38) directly comes from (9). Next, using (2) and (28), we directly get condition (39). Finally, the differentiation of (21) with respect to time leads to:

$$
\frac{\dot{V}_{H_{i}}}{V_{H_{i}}}=-\frac{\dot{H}_{R_{i}}^{i}}{H_{R_{i}}^{i}}, \quad i=\{B, E, S\} .
$$

Substituting this expression into (19) and using (21) again, it comes:

$$
r=-\frac{\dot{H}_{R_{i}}^{i}}{H_{R_{i}}^{i}}+v_{H_{i}} H_{R_{i}}^{i}, \quad \forall i=\{B, E, S\} .
$$

We thus obtain the three last characterizing conditions (40), (41) and (42) by replacing into this last equation $v_{H_{B}}, v_{H_{E}}$ and $v_{H_{S}}$ by their expressions (23), (24) and (25), respectively.

\section{A2. Proof of Proposition 2}

Let $H$ be the discounted value of the Hamiltonian of the optimal program (we drop time subscripts for notational convenience):

$$
\begin{aligned}
H= & U(C) e^{-\rho t}+\lambda Q\left\{K, E\left[F\left(Q_{F}, Z\right), B\left(Q_{B}, H_{B}\right), H_{E}\right], \Omega(T)\right\} \\
& -\lambda\left(C+Q_{F}+Q_{B}+Q_{S}+\delta K+\sum_{i} R_{i}\right)+\sum_{i} \nu_{i} H^{i}\left(R_{i}, H_{i}\right)+\eta F\left(Q_{F}, Z\right) \\
& +\mu_{G}\left\{\xi F\left(Q_{F}, Z\right)-S\left[F\left(Q_{F}, Z\right), Q_{S}, H_{S}\right]-\zeta G\right\}+\mu_{T}[\Phi(G)-m T]+\gamma_{G}(\bar{G}-G) .
\end{aligned}
$$


The associated first order conditions are:

$$
\begin{aligned}
\frac{\partial H}{\partial C} & =U^{\prime}(C) e^{-\rho t}-\lambda=0 \\
\frac{\partial H}{\partial Q_{F}} & =\lambda\left(Q_{E} E_{F} F_{Q_{F}}-1\right)+\eta F_{Q_{F}}+\mu_{G} F_{Q_{F}}\left(\xi-S_{F}\right)=0 \\
\frac{\partial H}{\partial Q_{B}} & =\lambda\left(Q_{E} E_{B} B_{Q_{B}}-1\right)=0 \\
\frac{\partial H}{\partial Q_{S}} & =-\lambda-\mu_{G} S_{Q_{S}}=0 \\
\frac{\partial H}{\partial R_{i}} & =-\lambda+\nu_{i} H_{R_{i}}^{i}=0, \quad i=\{B, E, S\} \\
\frac{\partial H}{\partial K} & =\lambda\left(Q_{K}-\delta\right)=-\dot{\lambda} \\
\frac{\partial H}{\partial H_{B}} & =\lambda Q_{E} E_{H_{i}}+\nu_{i} H_{H_{i}}^{i}=-\dot{\nu}_{i}, \quad i=\{B, E\} \\
\frac{\partial H}{\partial H_{S}} & =\nu_{S} H_{H_{S}}^{S}-\mu_{G} S_{H_{S}}=-\dot{\nu}_{S} \\
\frac{\partial H}{\partial Z} & =\lambda Q_{E} E_{F} F_{Z}+\mu_{G} F_{Z}\left(\xi-S_{F}\right)+\eta F_{Z}=-\dot{\eta} \\
\frac{\partial H}{\partial G} & =-\zeta \mu_{G}+\mu_{T} \Phi^{\prime}(G)-\gamma_{G}=-\dot{\mu}_{G} \\
\frac{\partial H}{\partial T} & =\lambda Q_{\Omega} \Omega^{\prime}(T)-m \mu_{T}=-\dot{\mu}_{T}
\end{aligned}
$$

The complementary slackness condition is:

$$
\gamma_{G}(\bar{G}-G)=0, \quad \text { with } \gamma_{G} \geq 0, \forall t \geq 0
$$

and the transversality conditions are:

$$
\begin{aligned}
\lim _{t \rightarrow \infty} \lambda K & =0 \\
\lim _{t \rightarrow \infty} \nu_{i} H_{i} & =0, \quad i=\{B, E, S\} \\
\lim _{t \rightarrow \infty} \eta Z & =0 \\
\lim _{t \rightarrow \infty} \mu_{G} G & =0 \\
\lim _{t \rightarrow \infty} \mu_{T} T & =0
\end{aligned}
$$

From (53), we find that $\eta=-\mu_{G}\left(\xi-S_{F}\right)-\lambda\left(Q_{E} E_{F}-1 / F_{Q_{F}}\right)$. Replacing this expression into (60) and using (52) leads to the following differential equation: $\dot{\eta}=$ $-\left(F_{Z} / F_{Q_{F}}\right) U^{\prime}(C) \exp (-\rho t)$. Integrating this expression and using the transversality condition (66), we obtain:

$$
\eta=\int_{t}^{\infty} \frac{F_{Z}}{F_{Q_{F}}} U^{\prime}(C) e^{-\rho s} d s
$$

Replacing into (53) $\lambda, \mu_{G}$ and $\eta$ by their expressions coming from (52), (55) and (69), respectively, gives us the equation (43) of Proposition 2. Equation (44) directly comes 
from condition (54). From (52) and (62), we have: $\dot{\mu}_{T}=m \mu_{T}-Q_{\Omega} \Omega^{\prime}(T) U^{\prime}(C) \exp (-\rho t)$. Using (68), the solution of such a differential equation is given by:

$$
\mu_{T}=\int_{t}^{\infty} Q_{\Omega} \Omega^{\prime}(T) U^{\prime}(C) e^{-[m(s-t)+\rho s]} d s .
$$

Next, log-differentiating (52) and (55) with respect to time yields:

$$
\begin{aligned}
\frac{\dot{\lambda}}{\lambda} & =\frac{\dot{U}^{\prime}(C)}{U^{\prime}(C)}-\rho \\
\frac{\dot{\mu}_{G}}{\mu_{G}} & =\frac{\dot{\lambda}}{\lambda}-\frac{\dot{S}_{Q_{S}}}{S_{Q_{S}}} .
\end{aligned}
$$

Using (63), equation (61) can be rewritten as $-\zeta \mu_{G}+\mu_{T} \Phi^{\prime}(G)+\dot{\mu}_{G} \geq 0$ (equality if $G<\bar{G}$ ) which, once $\lambda, \mu_{G}, \mu_{T}, \dot{\lambda}$ and $\dot{\mu}_{G}$ been respectively replaced by their expressions coming from (52), (55), (70), (71) and (72) implies condition (45). Condition (46) is a direct implication of equations (57) and (71). Finally, the log-differentiation of (56) with respect to time yields:

$$
\frac{\dot{\lambda}}{\lambda}=\frac{\dot{\nu}_{i}}{\nu_{i}}+\frac{\dot{H}_{R_{i}}^{i}}{H_{R_{i}}^{i}} .
$$

Conditions (47) and (48) come from (56), (58), (71) and (73), and from (54) by using $Q_{E} E_{B}=1 / B_{Q_{B}}$. Similarly, condition (49) is obtained from (55), (56), (59), (71) and (73).

\section{A3. Calibration of the model}

Here we provide some information on the calibration of key model parameters. According to IEA (2007), world carbon emissions in 2005 amounted to $17.136 \mathrm{MtCO}$. We retain 7.401 GtCeq as the initial fossil fuel consumption, given in gigatons of carbon equivalent. In addition, carbon-free energy produced out of renewable energy, excluding biomass and nuclear, represented $6 \%$ of total primary energy supply. We thus retain another 0.45 GtCeq as the initial amount of backstop energy use.

The introduction of a CCS production function necessitated the choice of additional parameters. The chosen functional specification is inspired from Gerlagh (2006). We retain his assumption as for the cost of CCS that is worth 150US\$/tC. According to IEA (2006), the cumulative CO2 storage capacity is in the order of 184 million tons per year. This value serves as a seed value for sequestration level, S0, in the initial year, which is then fixed at $0.05 \mathrm{GtC}$. The cost of CCS sequestration and the initial storage level allow for the calibration of the initial sequestration effort using the following relation: QS0/S0 $=\mathrm{CCS}$ cost $<=>$ QS0 $=0.05 \mathrm{GtC}^{*} 150 \$ / \mathrm{tC}=7.5 \mathrm{G} \$$. 
The rates of return on both $R \& D$ spending and knowledge accumulation have been set to 0.3 and 0.2 respectively so as provide long term sequestration in line with IPCC (2007) projections. Without loss of generality, the initial stock of knowledge H0 dedicated to CCS is set equal to 1 . This data is summarized in Table 2 below.

\begin{tabular}{|c|c|c|c|}
\hline Param. & Value & Description & Source \\
\hline$\gamma$ & 0.3 & Capital elasticity in output prod. & Nordhaus (2007b) \\
\hline$\beta$ & 0.07029 & Energy elasticity in output prod. & Nordhaus (2007b) \\
\hline$\alpha_{T}$ & 0.0028388 & Scaling param. on damage & Nordhaus (2007b) \\
\hline$\rho_{B}$ & & Elasticity of subs. for backstop & Calibrated \\
\hline$\rho_{E}$ & 0.38 & Elasticity of subs. for energy & Popp (2006a) \\
\hline$\alpha_{H}$ & 0.336 & Scaling param. of $H_{E}$ on energy & Popp (2006a) \\
\hline$F_{0}$ & 7.401 & 2005 fossil fuel use in GtC & IEA $(2007)$ \\
\hline$c_{F}$ & 400 & 2005 fossil fuel price in USD & Computed from IEA (2007) \\
\hline$\alpha_{F}$ & 700 & Scaling param. on fossil fuel cost & Popp (2006a) \\
\hline$\eta_{F}$ & 4 & Exponent in fossil fuel prod. & Popp (2006a) \\
\hline$B_{0}$ & 0.45 & 2005 backstop use in GtC & IEA $(2007)$ \\
\hline$\alpha_{B}$ & 1200 & 2005 backstop price in USD & Nordhaus (2007b) \\
\hline$\eta_{B}$ & & Exponent in backstop prod. & Calibrated \\
\hline$a_{B}$ & 0.0122 & Scaling param. in backstop innovation & Popp (2006a) \\
\hline$a_{E}$ & 0.0264 & Scaling param. in energy innovation & Popp (2006a) \\
\hline$b_{B}$ & 0.3 & Rate of return of backstop R\&D & Popp (2006a) \\
\hline$b_{E}$ & 0.2 & Rate of return of energy R\&D & Popp (2006a) \\
\hline$c_{S}$ & 150 & Sequestration cost in $2005 \mathrm{USD} / \mathrm{tC}$ & Gerlagh (2006) \\
\hline$S_{0}$ & 0.05 & 2005 sequestration in $\mathrm{GtC}$ & IEA $(2006)$ \\
\hline$Q_{S, 0}$ & 7.5 & 2005 sequestration effort in bill. USD & Calibrated \\
\hline$H_{S, 0}$ & 1 & 2005 level of knowledge in CCS & \\
\hline$R_{S, 0}$ & 0.5 & 2005 R\&D investment in CCS in bill. USD & \\
\hline$a_{S}$ & 0.5 & Scaling param. in CCS innovation & \\
\hline$b_{S}$ & 0.3 & Rate of return of CCS R\&D & \\
\hline$\phi_{S}$ & 0.2 & Elasticity of knowledge in CCS innovation & \\
\hline$\Phi_{i}$ & 0.54 & Elasticity of knowledge in innovation & Popp (2006a) \\
\hline$\epsilon$ & 2 & Elasticity of intertemporal subst. & Nordhaus (2007b) \\
\hline$A_{t}$ & & Total factor productivity trend & Nordhaus (2007b) \\
\hline$L_{t}$ & & World population trend & Nordhaus (2007b) \\
\hline$\rho_{t}$ & & Time preference rate & Nordhaus (2007b) \\
\hline$\ldots$ & & Other param. and initial values & Calibrated \\
\hline
\end{tabular}

Table 2: Calibration of parameters 